\title{
Expresión de PCNA, Cldn11, AR, PDGFRa y FoxL2 en ovoteste durante \\ el ciclo reproductivo de
}

T. occidentalis

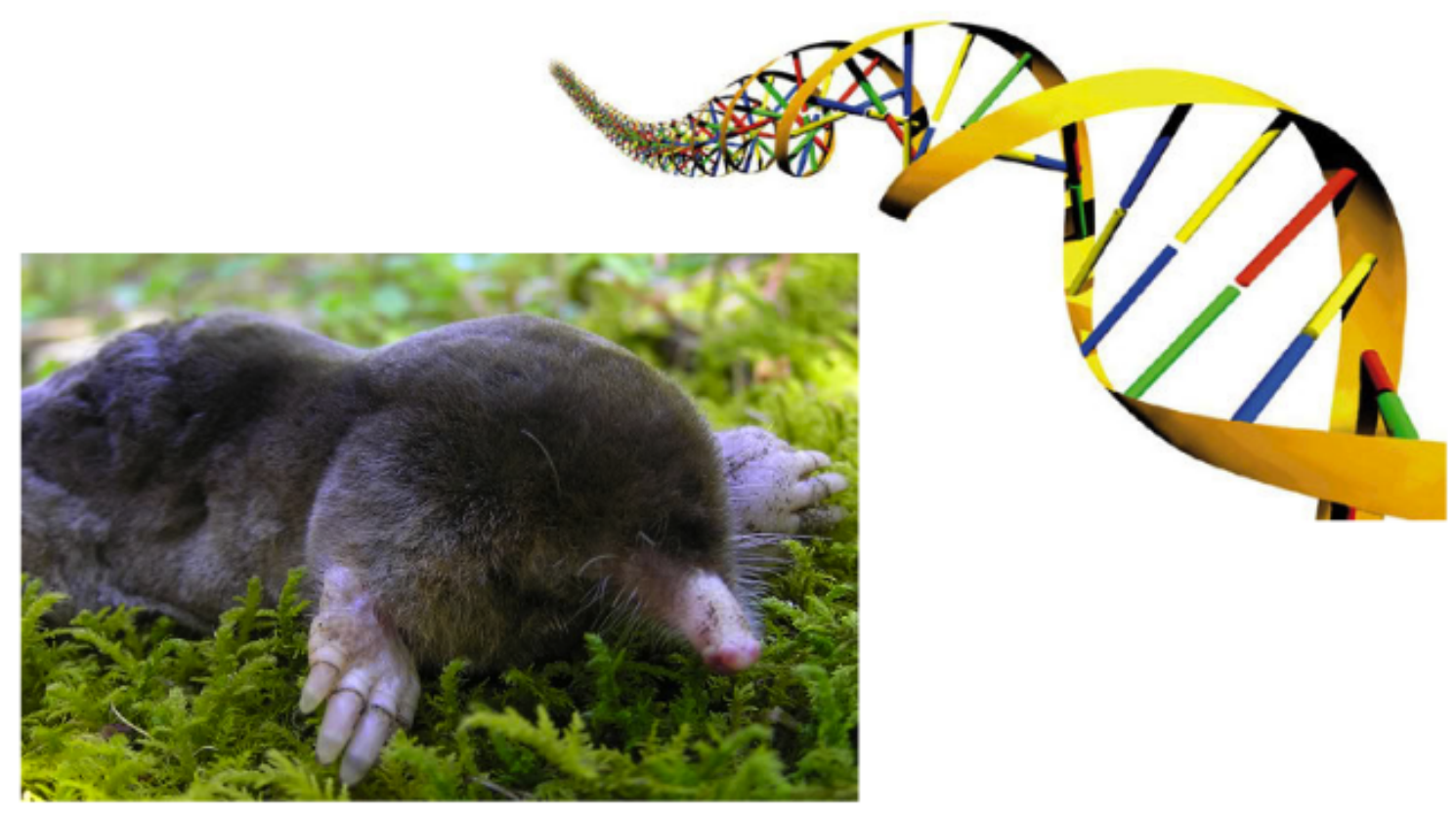

$M^{a}$ Carmen Garrido Navas Máster en Genética y Evolución 
Estudio de expresión de PCNA, Cldn11, AR, PDGFR $\alpha$ y FoxL2 en ovoteste durante el ciclo estacional de $T$. occidentalis

\section{$\mathrm{M}^{\mathrm{a}}$ Carmen Garrido Navas}

Septiembre de 2011 
Estudio de expresión de PCNA, Cldn11, AR, PDGFR $₫ y$ FoxL2 en ovoteste durante el ciclo estacional de T. occidentalis
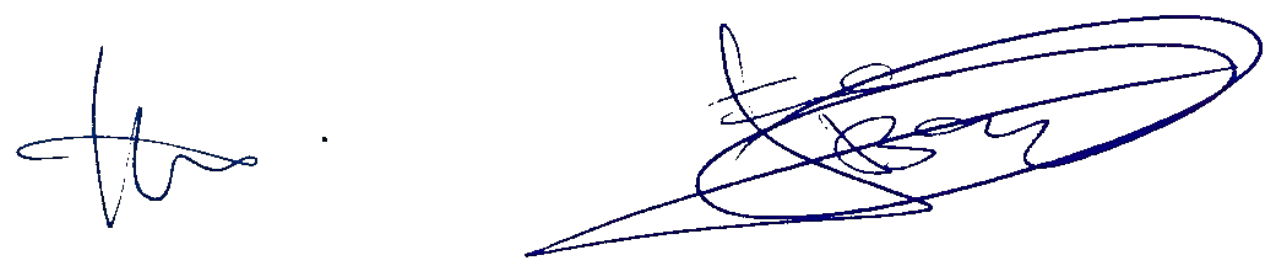

fdo. $\mathrm{M}^{\mathrm{a}}$ Carmen Garrido Navas

fdo. F.J. Barrionuevo Jiménez 


\section{Índice}

1. INTRODUCCIÓN 5

1.1. Reproducción estacional . . . . . . . . . . 5 5

1.2. Reproducción estacional en mamíferos . . . . . . . . . 6

1.3. Reproducción estacional en T. occidentalis . . . . . . . . 8

1.4. Genes de estudio . . . . . . . . . . . . . . . . 9

1.4.1. PCNA (proliferating cell nuclear antigen) . . . . . 9

1.4.2. CLDN11 (claudin 11) . . . . . . . . . . . . . 11

1.4.3. AR (androgen receptor) . . . . . . . . . . . . 13

1.4.4. PDGFR $\alpha$ (platelet-derived growth factor receptor) 15

1.4.5. FOXL2 (forkehead box L2) . . . . . . . . . . . . 17

1.5. Objetivo . . . . . . . . . . . . . . 18

2. MATERIAL Y METODOS 18

2.1. Material analizado . . . . . . . . . . . . . 18

2.2. Métodos . . . . . . . . . . . . . . . 18

2.2.1. Inclusión de material en parafina . . . . . . . . . 18

2.2.2. Procesado de los bloques y montaje de los cortes . 19

2.2.3. Inmunohistoquímica . . . . . . . . . . . . 19

3. RESULTADOS 23

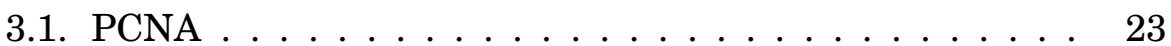

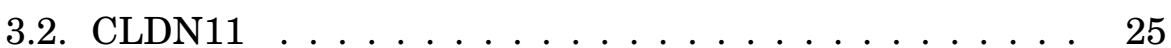

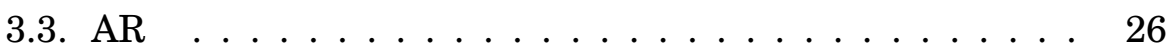

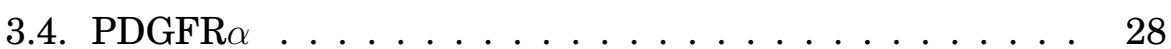

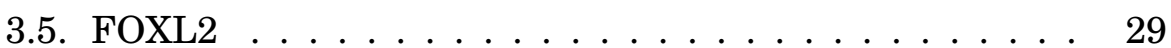

4. DISCUSION 31

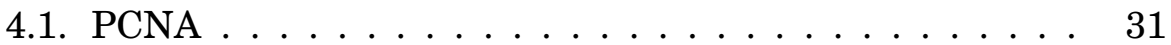

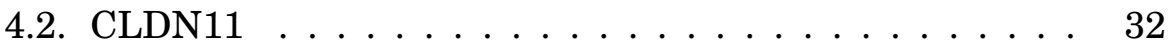

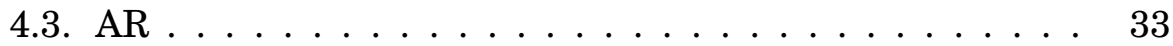

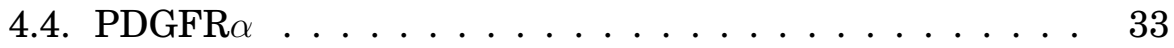

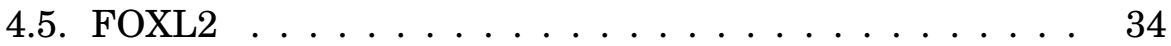

5. CONCLUSIONES 34

\section{Índice de figuras}

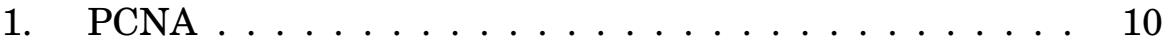


2. Claudin $11 \ldots \ldots \ldots \ldots \ldots \ldots$

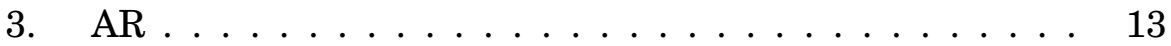

4. PDGFR $\alpha \ldots \ldots \ldots \ldots \ldots \ldots$

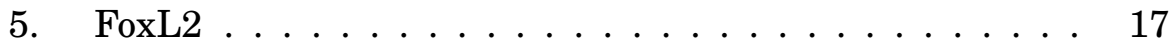

6. Resultados de expresión de PCNA en parte ovárica . . . 23

7. Resultados de expresión de PCNA en parte testicular . . 24

8. Resultados de expresión de Cldn11 en ovoteste . . . . . 25

9. Resultados de expresión de AR en parte ovárica . . . . . 26

10. Resultados de expresión de AR en parte testicular . . . . 27

11. Resultados de expresión de PDGFR $\alpha$ en ovoteste . . . . . 28

12. Resultados de expresión de FoxL2 en parte ovárica . . . . 29

13. Resultados de expresión de FoxL2 en parte testicular . . 30

\section{Índice de cuadros}

1. Anticuerpos primarios usados . . . . . . . . . . . . 22

2. Anticuerpos secundarios usados . . . . . . . . . . . 22 


\section{INTRODUCCIÓN}

\subsection{Reproducción estacional}

La vida de los seres vivos se ve influida por factores y elementos climáticos que pueden variar estacionalmente dependiendo de la región geográfica en la que nos encontremos (como ocurre en las zonas templadas y boreales). En estas zonas, el invierno es la estación que se presenta como un mayor reto para los seres vivos, que, a pesar de tener menor disponibilidad de recursos energéticos, muestran mayor requerimiento de éstos, debido a la necesidad de hacer frente al frío. Como consecuencia, los seres vivos experimentan modificaciones estacionales de procesos fisiológicos esenciales, que varían cíclicamente (Bronson, 1989; Bronson y Heideman, 1994). Ejemplos de estos procesos son: el crecimiento, las funciones endocrina, termogénica, inmunológica y, por supuesto, la reproducción (Moffatt et al., 1993). Los costes energéticos de estos procesos son intrínsecamente elevados, y cuando se combinan con la falta de alimento de los periodos invernales, la balanza de energía se inclina hacia funciones básicas que permitan la supervivencia de estos seres vivos (actividades básicas celulares, de tejido y de órgano, necesarias para la homeostasis, así como costes energéticos para la termorregulación y la alimentación). De esta forma, funciones como el crecimiento y la reproducción, pueden quedar retrasadas o abolidas para evitar un balance energético negativo (Bronson, 2009). La reproducción estacional provoca que tanto machos como hembras sufran numerosos y variados cambios cíclicos, afectando éstos a la práctica totalidad de su cuerpo. No obstante, caben destacar las modificaciones que se producen a nivel de sus órganos reproductores (gónadas), ya que implican una activación durante la época reproductora (generalmente en primavera y verano) y una inactivación durante la no reproductora (con frecuencia, en otoño e invierno) (Bronson y Heideman, 1994). Aunque los cambios se producen en ambos sexos, no podemos decir que sean iguales o equivalentes, ya que las demandas energéticas relacionadas con la reproducción son distintas para cada sexo; así pues, mientras que los costes para los machos son principalmente comportamentales (su éxito reproductivo viene determinado no sólo por la producción de semen, sino por la dominancia física frente a otros machos y a su capacidad de atraer hembras), en el caso de las hembras, las demandas energéticas derivadas de la lactancia (en mamíferos) y de los cuidados parentales suelen ser mucho más complejas (Bronson, 2009). 
Como vemos, la reproducción es uno de los procesos biológicos que más fuertemente se ve afectado por el clima. Teniendo en cuenta el inminente cambio climático que afecta a la Tierra, es lógico pensar que la eficiencia reproductiva de muchos organismos (incluidos los mamíferos, grupo al que pertenecemos), se vea alterada en un futuro próximo. Son animales que presentan sistemas ambientales de determinación sexual (reptiles entre los que encontramos cocodrilos y tortugas), los que muestran un ejemplo más claro del peligro que el cambio climático puede suponer para la supervivencia de determinadas especies. En estas especies, la temperatura de incubación de los huevos determina el sexo, por lo que, cualquier fluctuación térmica puede desemparejar la tasa de desarrollo de sexos (Neuwald y Valenzuela, 2011). En algunos casos, las altas temperaturas favorecen un sexo, y en otros casos, el contrario, pero como balance final, el resultado es el desequilibrio entre sexos, que podría llevar a la extinción de muchas de estas especies. En el caso de aves y mamíferos, la determinación del sexo es genética, lo que hace que la dependencia de las condiciones ambientales no sea tan relevante en cuanto a su desarrollo sexual, aunque, como hemos explicado anteriormente, sí que tiene cierta repercusión en cuanto al éxito reproductivo. El clima mundial está cambiando rápidamente y existe gran inquietud sobre la posible extinción de muchas especies que, al enfrentarse a estos cambios, no sean capaces de desarrollar nuevas estrategias estacionales (Bronson, 2009).

\subsection{Reproducción estacional en mamíferos}

La reproducción en mamíferos es un proceso complicado que debe ocurrir en armonía con unas condiciones sociales, físicas y dietéticas adecuadas (Bronson, 1985), por ello, debe estar perfectamente regulada, a nivel génico, endocrino y neuronal, siendo el eje hipotálamopituitaria-gónada (HPG) el encargado de controlar este proceso en vertebrados. Las neuronas GnRH están distribuidas ampliamente en el prosencéfalo, pero principalmente se encuentran en la parte anterior del hipotálamo y en el área preóptica (Bronson, 2009). La actividad de estas neuronas se ve influida por factores intrínsecos y extrínsecos, tales como las hormonas sexuales, el desarrollo, el estrés, la nutrición y la estación (Clarke y Pompolo, 2005). Las neuronas GnRH segregan, mediante pulsos intermitentes, un decapéptido llamado GnRH (gonadotropin-releasing hormone) que entra a la vasculatura portal de la pituitaria (hipófisis), donde regula la síntesis y secreción de gonadotropinas (Sisk y Foster, 2004). Las gonadotropinas son hormonas glico- 
proteícas y heterodiméricas, que están glicosiladas (Bousfield y Dias, 2011). Durante la pubertad o en el proceso de reactivación de la función sexual en especies con reproducción estacional, se liberan dos de éstas hormonas: LH (hormona luteinizante) y FSH (hormona folículoestimulante), que viajan por la sangre y cuyas células diana son testículos y ovarios. Sobre éstos actúan, activando la producción de gametos y de hormonas sexuales (esteroideas), siendo fundamentales tanto para la función gonadal como para el comportamiento reproductivo (Sisk y Foster, 2004). En la gónada, las hormonas esteroideas participan en la espermatogénesis y en la maduración folicular; en el cerebro, influyen en los bucles de retroalimentación por vía neuroendocrina de secreción de GnRH, y facilitan el comportamiento sexual.

La mayoría de especies con reproducción estacional utiliza el fotoperiodo como el principal factor ambiental para obtener información estacional, siendo éste el resultado de un proceso adaptativo que permite a estas especies hacer coincidir los nacimientos con la estación del año energéticamente más favorable en cada caso. La respuesta al fotoperiodo en mamíferos no está sólo basada en la longitud absoluta del día, sino también en la historia fotoperiódica de los animales (Malpaux et al., 2001); por ello, exposiciones a un mismo fotoperiodo pueden producir efectos opuestos dependiendo del animal y de su historia evolutiva (Robinson y Karsch, 1988). El complejo sistema neuroendocrino que percibe el fotoperiodo en mamíferos está constituido por la retina, el núcleo supraquiasmático y la glándula pineal (Malpaux et al., 2001), siendo esta última la que produce y libera melatonina. Esta secreción es exclusivamente nocturna, pero mientras que en algunas especies (ovejas, etc), dura todo el periodo de oscuridad, en otras (hámster sirio, rata, etc), la secreción no empieza hasta pasadas unas horas de oscuridad (Arendt, 1995). Parece ser que la característica más importante del ritmo secretor de la melatonina es la duración (tiempo que permanece a niveles elevados) (Malpaux et al., 2001), por ello, a lo largo del año, esta duración de la secreción varía estacionalmente y proporciona una representación endocrina del fotoperiodo. Estas variaciones actúan como señales que regulan la secreción de GnRH mediante dos mecanismos complementarios: una modulación directa independiente de esteroides de la secreción de GnRH y un cambio en la retroalimentación negativa mediada por esteroides de la secreción de GnRH (Goodman, 1994). No obstante, apenas se conocía algo sobre el mecanismo de acción de la melatonina sobre las neuronas productoras de GnRH hasta el descubrimiento de uno de los intermediarios esenciales: el complejo formado por las kisspeptinas. Son un conjunto de péptidos de distintas 
longitudes, productos del gen Kiss1 que, junto con su receptor GPR54, juegan un papel importante en la regulación de la reproducción. De hecho, mutaciones en humanos, o deleciones dirigidas en ratones, bien de Kiss1 o de su receptor, causan hipogonadismo hipogonadotrófico profundo (Oakley et al., 2009). En el hámster sirio se ha demostrado que la actividad reproductora es promovida por los días largos de verano e inhibida por los días cortos de invierno, ya que los niveles de mRNA de Kiss1 aparecen regulados por la melatonina en las células del hipotálamo encargadas de producir GnRH (Revel et al., 2006). Además, hay descritos múltiples experimentos en hámsters y otras especies que han demostrado que la alteración del fotoperiodo tiene efectos evidentes en la función gonadal (Moffatt-Blue et al., 2006; Beery et al., 2007; Trainor et al., 2007, 2008; Vrooman y Young, 2010).

\subsection{Reproducción estacional en $T$. occidentalis}

El topo ibérico Talpa occidentalis (Cabrera, 1914) es un mamífero perteneciente al nuevo orden Eulipotyphla (derivado del antiguo orden Insectívora), que se distribuye por toda la Península Ibérica, excepto en determinadas áreas del Norte y Noroeste, que se encuentran habitadas por la especie Talpa europaea. Los topos presentan una reproducción estacional cuyos ciclos varían según la latitud (Jimenez et al., 1990) y en el Sur de la Península Ibérica abarca desde Noviembre hasta Marzo, pudiendo variar estos límites de un periodo reproductivo a otro. El periodo de gestación consta de 29 días con una media de 4 crías por camada. Durante cada periodo reproductor, las hembras quedan preñadas hasta un máximo de 2 veces. En 1988, Jiménez et al. describieron en Talpa occidentalis el único caso conocido hasta la fecha, en mamíferos euterios, de hermafroditismo verdadero que afecta a todas las hembras de una misma especie. Estas hembras presentan ovotestes bilaterales con tejido testicular y ovárico simultáneamente, en lugar de ovarios y no obstante, su función reproductora no se ve alterada. Posteriormente, se ha comprobado que otras muchas especies de topos (familia Talpidae) presentan este singular y complejo desarrollo ovárico. Estos ovotestes XX han sido descritos en diversas especies europeas del género Talpa, T. europaea, T. romana y T. stankovici (Jiménez et al., 1993; Sánchez et al., 1996; Mathews, 1935; Popoff, 1911), el desmán Galemys pyrenaicus (PEYRE, 1962), el topo de nariz estrellada Condylura cristata (Mossman, 1973; Rubenstein et al., 2003), el topo musaraña americano (Rubenstein et al., 2003) y el topo japonés Mogera wogura (Carmona et al., 2008). Esto indica que podría tratar- 
se de una característica adquirida por algunas especies de este grupo taxonómico.

La porción ovárica del ovoteste contiene oocitos maduros durante el periodo reproductor y es completamente funcional, mientras que la parte testicular no presenta células germinales y es de mayor tamaño que la ovárica. Esta porción testicular desarrolla numerosas características específicas de testículos, como la diferenciación de células de Leydig, productoras de testosterona (que convierte a estas hembras en territoriales y agresivas en los períodos infértiles). Anualmente, ambas porciones alternan ciclos de regresión y crecimiento. Durante la época reproductiva, la parte ovárica predomina sobre la testicular, y en la época de descanso ocurre lo contrario, detectándose altos niveles circulatorios de testosterona de la región testicular, que desaparecen en la época fértil (Jiménez et al., 1993). En los testículos de los machos, que presentan un desarrollo gonadal muy similar al del resto de mamíferos, también se han observado cambios de morfología con respecto a los ciclos estacionales. Durante periodos de inactividad, el testículo sufre una reducción de un $80-90 \%$ de su masa, como consecuencia de una reducida proliferación de las espermatogonias que también origina que haya un bajo número de células germinales. La apoptosis parece no ser la causa de la masiva depleción de células germinales (Dadhich et al., 2010). Una oleada de proliferación restaura las espermatogonias perdidas durante el periodo de inactividad. $\mathrm{Al}$ contrario que en otras especies con reproducción estacional, en este caso el fotoperiodo parece ejercer una menor influencia sobre estos cambios morfológicos ya que, por tener una vida principalmente subterránea, los topos pueden presentar dificultad para percibir cambios en la longitud del fotoperiodo.

\subsection{Genes de estudio}

\subsubsection{PCNA (proliferating cell nuclear antigen)}

Este gen se encuentra localizado en el locus 20pter-p12 del cromosoma 20 humano y tiene un tamaño aproximado de $11 \mathrm{~Kb}$. Hay dos transcritos para este gen, de longitudes 1344 y 1359 bp respectivamente, codificando cada uno, la misma secuencia de 261 aminoácidos. Como se muestra en la figura 1, tiene 6 exones y 5 intrones.

PCNA es una proteína nuclear de $36 \mathrm{kDa}$ altamente conservada que actúa como proteína auxiliar de la DNA polimerasa, funcionando durante la replicación, elongación del DNA y reparación por excisión (Bravo y Macdonald-Bravo, 1987; Prelich et al., 1987; Madsen y Celis, 


\section{II}

a
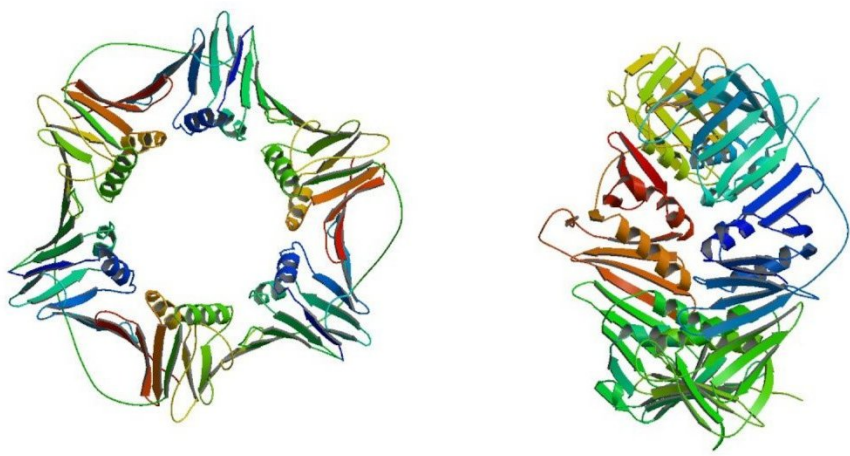

b

Figura 1: PCNA: a Transcrito de 1344 bp codificado por el gen PCNA que da lugar a la proteína funcional. Su estructura secundaria consta de 6 hélices $\alpha, 20$ láminas $\beta$ y un giro, agrupándose en 6 exones. b Estructura terciaria de la proteína codificada por PCNA. Homotrímero con una región potencial de unión al DNA que consta de 20 bp, la cual permite albergar en su cavidad central la cadena dúplex de DNA, además de una región de 94 bp que interacciona con NUDT15 
1985). Los patrones temporales de expresión de PCNA la convierten en una herramienta interesante para el estudio de la proliferación celular, ya que empieza a acumularse en la fase G1 del ciclo celular, alcanzando su máximo nivel de expresión durante la fase $\mathrm{S}$ y decreciendo durante G2/M (Kurki et al., 1988). La expresión de PCNA se ha localizado en el ovario de diferentes especies de mamíferos, entre las que se encuentran el ratón (Chapman y Wolgemuth, 1994) la rata (Oktay et al., 1995), la vaca (Wandji et al., 1996), el babuino (Wandji et al., 1997) y el cerdo (Tománek y Chronowska, 2006), así como en testículos de otras tantas especies (Chapman y Wolgemuth, 1994; Chieffi et al., 2001). Chapman y Wolgemuth (1994) describieron la expresión de este gen en ovario y testículo de ratón, resumiéndose como sigue:

Ovario: no se observó expresión en folículos primordiales. En folículos primarios y secundarios se observa expresión en el núcleo de los oocitos y apenas expresión en células de la granulosa, mientras que en folículos en crecimiento activo y preantrales, se observa expresión en células de la granulosa y de la teca. No se observa expresión en células del cuerpo lúteo aunque células de la granulosa de folículos atrésicos sí tienen expresión.

Testículos: la expresión de PCNA se observa en el núcleo de espermatogonias que se están dividiendo y en algunos espermatocitos primarios (leptotene, zigotene y paquitene temprano), mientras que no se observa expresión en espermatocitos secundarios ni espermátidas. También se observa expresión en las células de Leydig intersticiales (aunque esta expresión no es específica).

\subsubsection{CLDN11 (claudin 11)}

Este gen comprende la región 3q26.2-q26.3 del cromosoma $3 \mathrm{hu}$ mano y tiene un tamaño aproximado de $440 \mathrm{~Kb}$. Tiene hasta 10 transcritos, de los cuales solo 3 dan lugar a proteína. El transcrito que da lugar a CLDN11 tiene una longitud de 2169 bp y se traduce en una proteína de 207 aminoácidos. Como se muestra en la figura 2 , tiene 3 exones y 2 intrones.

CLDN11 también es conocida como proteína específica de oligodendrocitos (OSP) y pertenece a la familia de las moléculas de adhesión (JAM). Se describió por primera vez en la vaina de mielina del sistema nervioso central (Bronstein et al., 1996). Las claudinas junto con las ocludinas, son moléculas de adhesión que contienen cuatro dominios 


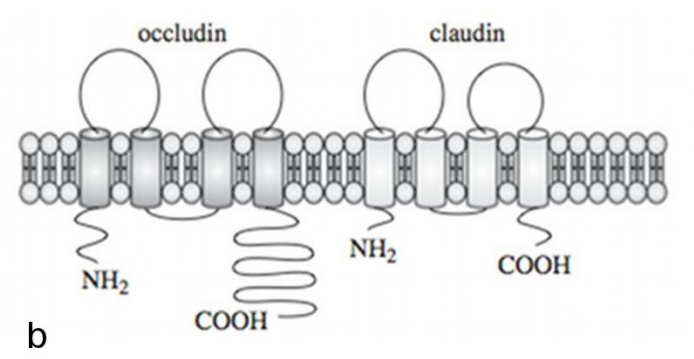

Figura 2: Claudin 11: a Transcrito de $440 \mathrm{~Kb}$ codificado por el gen Cldn11 que da lugar a la proteína funcional y que consta de 3 intrones. b Esquema de la estructura terciaria de Cldn11. Consta de 4 hélices transmembrana, 2 dominios extracelulares y 3 dominios intracelulares (incluyendo los extremos $\mathrm{N}$ y $\mathrm{C}$ terminal).

transmembrana, dos bucles extracelulares, un pequeño bucle intracitoplasmático corto y los dominios $\mathrm{N}$ y $\mathrm{C}$ terminal citoplasmáticos. Cldn11 se expresa específicamente en oligodendrocitos en el cerebro y en células de Sertoli en el testículo, donde forma la barrera hematotesticular. Es aquí donde se ha comprobado que su expresión está regulada hormonalmente por FSH y testosterona (Hellani et al., 2000; Gye, 2003). La barrera hematotesticular (BTB: Blood-Testis Barrier) está formada por uniones estrechas (TJs: Tight Junctions) entre las células de Sertoli adyacentes y divide el epitelio seminífero en dos compartimentos: basal y adluminal (Mruk y Cheng, 2004). Las espermatogonias y los espermatocitos primarios se encuentran por debajo del compartimento basal y los espermatocitos secundarios y espermátidas por encima, en el compartimento adluminal (Morrow et al., 2010). Esta separación física establece las condiciones del microambiente necesarias para la meiosis de las células germinales y la maduración de los diferentes tipos de células germinales. Se han establecido relaciones directas entre las proteínas que unen a células de Sertoli y los andrógenos, que parecen regular positivamente la expresión de mRNA de claudin 11 en cultivos primarios de células de Sertoli de rata y ratón (Gye, 2003). Además, se ha observado que la testosterona aumenta de forma significativa, entre dos y tres veces, la formación de estas TJs in vitro (Kaitu'u-Lino et al., 2007), aunque los resultados in vivo sugieren que múltiples fac- 
tores además de estos ya mencionados, controlan la expresión basal de mRNA de cldn11 (Morrow et al., 2010). Los niveles de mRNA de cldn11 se inhiben exclusivamente en presencia de espermátidas, lo que apoya el efecto inhibidor postmeiótico de las células germinales (Florin et al., 2005). En varias especies de hámster y visón, las TJs que comprenden la BTB sufren roturas cíclicas y reapariciones en asociación con el fotoperiodo y cambios en las gonadotropinas circulantes (Kaitu'u-Lino et al., 2007), como ocurre en el hámster Djungarian en el que, en los días cortos en los que las gonadotropinas en suero se presentan en bajas concentraciones, hay una falta funcional de estas TJs (Bergmann, 1987).

\subsubsection{AR (androgen receptor)}

Este gen se encuentra localizado en el locus Xq12 del cromosoma $\mathrm{X}$ humano y tiene un tamaño aproximado de $185 \mathrm{~Kb}$. Tiene hasta 8 transcritos de los cuales dos (de 10065 y 1728 bp respectivamente) son los que dan lugar a las dos isoformas de AR, que constan de 920 y 388 aminoácidos respectivamente. Ambas isoformas tienen 8 exones y 7 intrones, como se muestra a continuación.
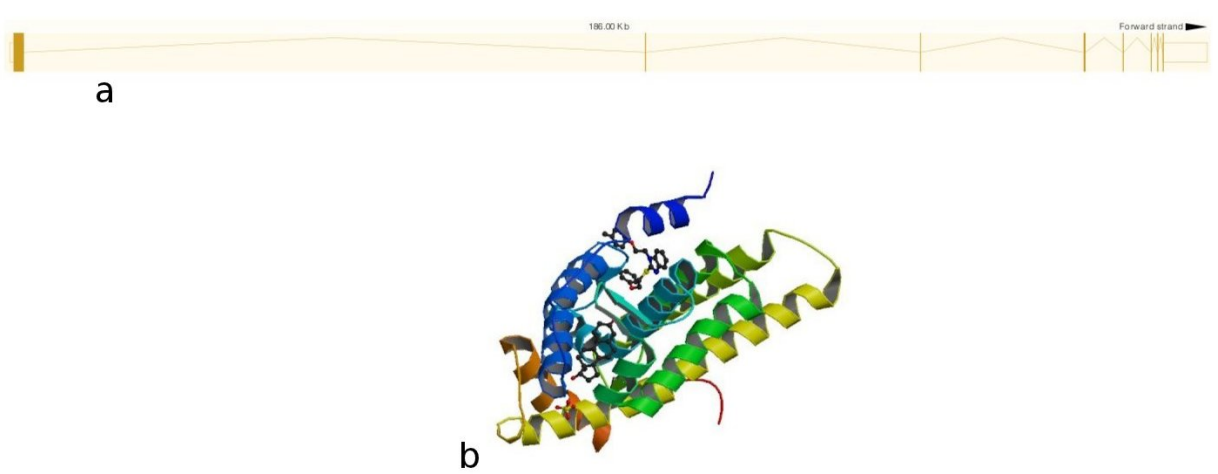

Figura 3: AR: a Transcrito de 10065 bp codificado por el gen AR que da lugar a la proteína funcional y que consta de 8 exones. b Estructura terciaria de AR, compuesta por un dominio N-terminal modulador, una región de unión al DNA con estructura en dedos de zinc y el dominio C-terminal de unión a ligando. Es necesaria la unión de cofactores para la dimerización y unión al DNA diana.

Los andrógenos son hormonas esteroideas que determinan la expresión fenotípica de macho, incluyendo los caracteres sexuales secunda- 
rios, además de la iniciación y el mantenimiento de la espermatogénesis. Su acción está mediada por el receptor de andrógenos (AR), un miembro de la superfamilia de receptores nucleares. AR está codificado por un gen que se localiza en el cromosoma $\mathrm{X}$ y actúa como factor de transcripción inducible por ligando, modulando la expresión de genes diana (Lubahn et al., 1988; Chang et al., 1988). La unión de AR con su ligando testosterona o su metabolito DHT (5-alpha-dihidrotestosterona), induce la dimerización del receptor, lo que facilita la capacidad de AR de unirse a sus elementos de respuesta conocidos y reclutar correguladores para promover la expresión de sus genes diana (Quigley et al., 1995; Heinlein y Chang, 2002). Fallos en este receptor causan una serie de desórdenes hereditarios denominados Síndrome de Insensibilidad a Andrógenos (AIS) o mutaciones de feminización testicular (Tfm) (Griffin, 1992; Spada et al., 1991; McPhaul, 1999; Quigley et al., 1995). En el ratón, AR se expresa en células de Leydig, mioides y de Sertoli (Zhou et al., 2002); no obstante, aunque la expresión en células de Leydig y mioides es continua, en células de Sertoli, ocurre de un modo dependiente del estadío. Coincide que cuando la expresión de AR es fuerte en células de Sertoli, se produce una mayor retirada de andrógenos, y puesto que estas células están en contacto directo con las células germinales (en las que la expresión de AR es más controvertida), se puede pensar que son estas células los principales mediadores de la regulación de la espermatogénesis mediante AR (Holdcraft y Braun, 2004). Además de expresarse en testículo, AR se expresa, entre otros tejidos, en hipotálamo, pituitaria y varias células ováricas, aunque su papel específico en la regulación de la fertilidad femenina permanece incierto (Sen y Hammes, 2010). En hembras de primates, se ha encontrado expresión en células de la granulosa de folículos antrales y preantrales, estando ausente en folículos preovulatorios y cuerpos lúteos (Hillier et al., 1997). Hembras de ratón knock-out (ARKO) presentan fertilidad reducida, tienen fallos en la foliculogénesis y desarrollan fallo ovárico prematuro. Además, tienen bajo número de folículos atrésicos, pocos cuerpos lúteos y altas tasas de apoptosis de células de la granulosa (Hu et al., 2004; Walters et al., 2007). Hay diversos trabajos que estudian la expresión de AR en ovarios de roedores (Hirai et al., 1994; Tetsuka y Hillier, 1996; Szołtys y Słomczyńska, 2000; Gilling-Smith et al., 1994), cerdos (Słomczyńska et al., 2001; Cárdenas y Pope, 2002), ganado ovino y bovino (Juengel et al., 2006; Hampton et al., 2004) y humanos (Suzuki et al., 1994; Chadha et al., 1994; Horie et al., 1992). En ellos, suele observarse expresión en mayor o menor grado en células de la granulosa, en función del grado de desarrollo (suele descender en folículos madu- 
ros) y en células de la teca y oocitos. Cuando la señalización mediada por AR está bloqueada o eliminada, los folículos preantrales no pueden progresar a folículos antrales, y por lo tanto, se produce un aumento de atresia, lo que podría explicar el bajo número de folículos antrales y cuerpos lúteos, además de bajo número de oocitos, en ratones ARKO (Sen y Hammes, 2010).

\subsubsection{PDGFR $\alpha$ (platelet-derived growth factor receptor)}

Este gen se encuentra localizado en el locus 4q12 del cromosoma 4 y tiene un tamaño aproximado de $69 \mathrm{~Kb}$. Tiene hasta 10 transcritos, de los cuales el que da lugar a la secuencia codificante tiene una longitud de 6576 bp. La proteína resultante tiene 1089 aminoácidos y consta de 23 exones y 22 intrones como se muestra en la imagen 4.

a

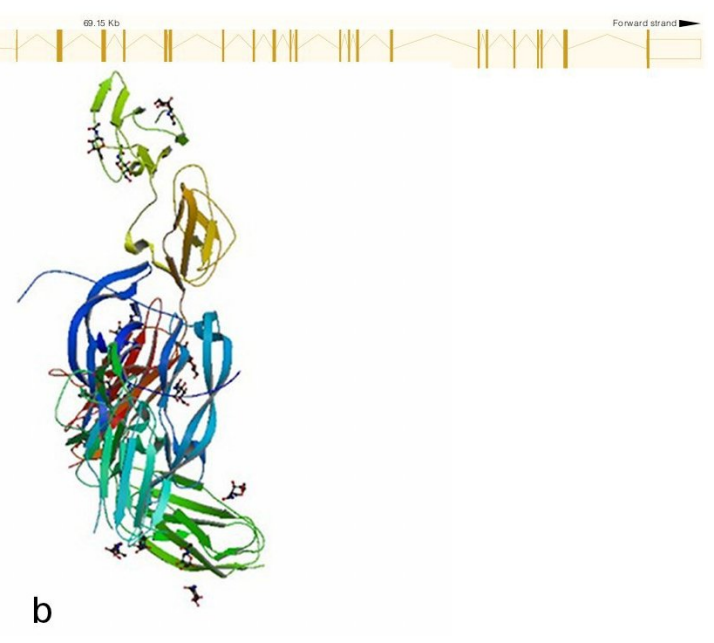

Figura 4: PDGFR $\alpha$ : a Transcrito de $69 \mathrm{~Kb}$ codificado por el gen PDGFR $\alpha$ que da lugar a la proteína funcional y que consta de 23 exones. b Estructura terciaria de PDGFR $\alpha$. La proteína consta de un dominio de activación que acepta protones, un dominio de unión al ATP, una hélice $\alpha$ transmembrana, un dominio proteín kinasa, seis dominios Ig-like C2 y una zona rica en serinas.

Los factores de crecimiento derivados de plaquetas son una familia de señales moleculares que fueron identificadas por primera vez como factores del suero que estimulaban la proliferación de las células mioides de las arterias (Ross et al., 1978). Desde entonces, han sido ampliamente estudiados, mostrando ser fundamentales en diversos procesos 
biológicos, como la proliferación, supervivencia y migración celular y la deposición de la matriz extracelular. Esta familia está compuesta por cuatro ligandos, PDGF-A, PDGF-B, PDGF-C y PDGF-D, que pueden formar diferentes combinaciones de homo y heterodímeros que se unen a uno de los dos receptores: PDGFR $\alpha$ o PDGFR $\beta$ (Heldin, 1996). Generalmente, los ligandos PDGF son sintetizados por células epiteliales o endoteliales, mientras que los receptores se suelen encontrar en las células mesenquimáticas. La proliferación y migración de las células mesenquimáticas en respuesta a estos factores, contribuye a la morfogénesis e integridad de diversos órganos (Hoch y Soriano, 2003). PDGFR $\alpha$ es esencial para la proliferación de células mesenquimáticas durante el desarrollo temprano del intestino, la piel, los pulmones, los riñones y las gónadas, además de estar implicado en procesos de crecimiento celular (Heldin, 1996; Raines y Ross, 1990), reorganización de actina (Eriksson et al., 1992) y quimiotaxis (Hossain et al., 1998; Kaplan et al., 1979; Shure et al., 1992; Yu et al., 1991) entre otros. La migración de células del mesonefros hacia la gónada embrionaria es necesaria para la formación de testículos en el ratón (Smith et al., 2005), y puesto que en los procesos de migración hace falta algún tipo de respuesta quimiotáctica, parecen verse implicados estos receptores PDGFR $\alpha$, no sólo en los mamíferos, sino también en aves, como Smith et al. (2005) han demostrado. Sorprendentemente, en el transcurso de esta migración, PDGFR $\alpha$ sólo está presente en las células de la gónada, no detectándose expresión en las células mesonéfricas. Este hecho sugiere que las señales PDGF no inducen directamente la migración celular, aunque sí son necesarias como segundos mensajeros para que ésta se lleve a cabo (Brennan et al., 2003). Recientemente, también se ha encontrado expresión tanto del receptor como del ligando en oocitos, células de la teca y células del estroma ovárico (Pinkas et al., 2008). En topos, se ha estudiado en el macho, la expresión de este receptor (Carmona et al., 2009), mostrando que es transitoria durante la diferenciación del testículo. La máxima inmunoreactividad se observa en gónadas del estadio s5a a partir del cual, la expresión va decreciendo hasta desaparecer, quedando sólo expresión fuera de los cordones testiculares. Esta expresión coincide con la presencia de precursores de las células de Leydig, que acaban diferenciándose en s5c, justo cuando deja de expresarse PDGFR $\alpha$, lo que demuestra que estos receptores están implicados también en la diferenciación de células de Leydig en el testículo (Gnessi et al., 1995; Brennan et al., 2003; Ricci et al., 2004). 


\subsubsection{FOXL2 (forkehead box L2)}

Este gen se encuentra localizado en el locus 3q22.3 del cromosoma 3 de humanos. Tiene dos transcritos, de los cuales, solo uno da lugar a la proteína, que consta de un único exón y está compuesta por 376 aminoácidos.

a

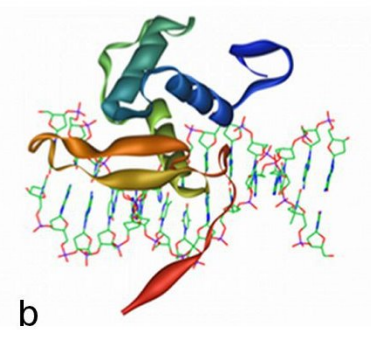

Figura 5: FoxL2: a Transcrito de 2917 bp codificado por el gen FoxL2 que contiene un único exón. b Estructura terciaria de FoxL2 que tiene una región de unión al DNA de tipo Fork-head; además, tiene dos regiones de poli-alanina, una región de poli-glicina y una región de poli-prolina.

Este gen pertenece a la familia de factores de transcripción family winged helix/forkhead cuyas mutaciones son causa de numerosas enfermedades que afectan al desarrollo, mostrando fenotipos pleiotrópicos con defectos oculares, craneofaciales, circulatorios, esqueléticos, inmunes y gonadales. Estudios de mapeo cromosómico en individuos que presentaban síndromes de blepharophimosis/ptosis/epicanthus inversus (BPES) tipo I (que lleva asociado fallo ovárico prematuro) y tipo II, permitieron identificar mutaciones en este gen (Crisponi et al., 2001). FoxL2 juega un papel importante durante el desarrollo ovárico. En ovarios mutantes homozigotos para foxl2-, las células de la granulosa no llegan a completar la transición de escamosas hasta cuboidales, lo que ocasiona la ausencia de folículos y atresia de oocitos (Schmidt et al., 2004). Además, este gen parece ser necesario en la regulación de la secreción de gonadotropinas. Se han descrito dos dianas para FoxL2 en pituitaria, GnRH y A-GSU (Ellsworth et al., 2003, 2006). En humanos, FoxL2 se detecta en el ovario de la gónada inmadura, mostrando una fuerte expresión en el núcleo de células de la granulosa y una expresión menor en las células del estroma durante el desarrollo fetal. Este 
patrón de expresión continúa en el adulto. Sin embargo, en gónadas $\mathrm{XY}$ no se detecta expresión de este gen. Se han hecho estudios de expresión en otras especies, como el ratón (Schmidt et al., 2004), el pollo (Govoroun et al., 2004) y tortuga (Loffler et al., 2003) entre otras.

\subsection{Objetivo}

El objetivo de este trabajo, consiste en estudiar las diferencias de expresión de una serie de proteínas para estudiar su posible implicación en los cambios morfológicos y funcionales que ocurren durante la reproducción estacional de la especie $T$. occidentalis, cuyas hembras presentan ovotestes. Compararemos los perfiles de expresión de la porción ovárica y de la testicular, en dos periodos reproductivos, fértil e infértil y contrastando nuestros resultados con los de estudios previos en otras especies, estableceremos papeles potenciales que estos genes pueden desempeñar bien en la regulación de la foliculogénesis, bien en la de la secreción de gonadotropinas durante la reproducción estacional.

\section{MATERIAL Y METODOS}

\subsection{Material analizado}

Para realizar este Trabajo de Fin de Máster se han usado ovotestes de dos individuos hembras, de la especie de topo Talpa occidentalis. Uno de ellos fue capturado en Julio, por lo que se encontraría en periodo infértil, y otro, capturado en Febrero, siendo una hembra preñada, y por tanto, encontrándose en periodo fértil.

\subsection{Métodos}

\subsubsection{Inclusión de material en parafina}

Tras la extracción del material, las gónadas fueron fijadas en paraformaldehido al $4 \%$ no más de 24 horas. A continuación, se deshidrata la muestra y se incluye según los siguientes pasos:

- Dos lavados de PBS de 20 minutos cada uno

- Series de etanol:PBS : 50\%, 70\%, $96 \%, 100 \%$. Se dejan 20 minutos en cada solución 
- Etanol $100 \%$ toda la noche a $-20{ }^{\circ} \mathrm{C}$

- Etanol $100 \%$ durante 2 horas a $4{ }^{\circ} \mathrm{C}$

- Mezcla etanol absoluto:xileno 1:1 durante 1 hora a temperatura ambiente

- Xileno durante 1 hora a temperatura ambiente

- Xileno durante 1 hora. En este paso se colocan las piezas en una estufa a $60^{\circ} \mathrm{C}$ para que se calienten gradualmente

- Mezcla xileno:parafina 1:1 durante 1 hora a $60{ }^{\circ} \mathrm{C}$

- Parafina durante $12-24$ horas a $60{ }^{\circ} \mathrm{C}$

- Parafina nueva durante $4-5$ horas a $60{ }^{\circ} \mathrm{C}$

- Orientación de los bloques en moldes de plástico. Dejar solidificar 4-5 horas a temperatura ambiente

- Almacenaje de los bloques a $4{ }^{\circ} \mathrm{C}$ hasta su uso

\subsubsection{Procesado de los bloques y montaje de los cortes}

Las piezas incluidas se cortaron de forma seriada $(5-7 \mu \mathrm{m})$ utilizando un microtomo rotativo tipo Minot. Para lo obtención de las preparaciones histológicas, se depositaron los cortes en portaobjetos tratados con polilysina (Polysine, VWR International, Belgium) a los que previamente se les aplicó una gota de agua destilada. Los portaobjetos se colocaron en una placa termostática estabilizada a $37^{\circ} \mathrm{C}$ ya que a esta temperatura la parafina se extiende mejor sin llegar a fundirse. Las preparaciones se dejan toda la noche a esta temperatura para favorecer la evaporación del agua y a la mañana siguiente se almacenan a 4 ${ }^{\circ} \mathrm{C}$ hasta su uso.

\subsubsection{Inmunohistoquímica}

Con esta técnica se estudia el patrón de expresión de diversos genes detectando la presencia o ausencia de las proteínas que codifican, mediante el uso de anticuerpos específicos. La señal se obtiene gracias a un anticuerpo secundario conjugado con fosfatasa alcalina, que al contacto con $\mathrm{DAB}$ origina un precipitado marrón. Para realizar esta técnica, se usó el siguiente protocolo: 
- DIA 1

- Calentar las preparaciones en una placa termoestable estabilizada a $60^{\circ} \mathrm{C}$ hasta que se funda la parafina (aproximadamente 20 minutos)

- Desparafinar, aplicando 2 lavados de xileno de 20 minutos cada uno

- Rehidratar las muestras en una serie de alcoholes de mayor a menor gradación (EtOH 100\%, 75\%, 50\%) dejándolas 5 minutos en cada uno

- Lavar 2 veces en PBT (Tween20 al 0,1\% en PBS) durante 10 minutos

- Recuperación de antígeno (antigen retrieval): se mezclan 2,2 $\mathrm{g}$ de Tris-Base y 0,86 g de EDTA en $500 \mathrm{ml}$ de agua destilada. Se colocan las preparaciones en un recipiente con esta solución y se introduce en el microondas, durante 10 minutos a máxima potencia. Transcurrido ese tiempo, se añaden 100 $\mathrm{ml}$ de agua destilada al recipiente y se vuelve a calentar a máxima potencia durante otros 10 minutos.

- Dejar enfriar durante 30-40 minutos dentro del microondas

- Lavar 2 veces en PBT durante 10 minutos

- Bloqueo utilizando el suero de la especie en que se ha sintetizado el anticuerpo secundario, al $2 \%$ en PBT durante 1 hora a temperatura ambiente en cámara húmeda

- Incubación con el anticuerpo primario diluido 1:75 en la solución de bloqueo en cámara húmeda durante toda la noche a $4{ }^{\circ} \mathrm{C}$. Ver Cuadro 1 para más información.

- DIA 2

- Lavar 3 veces con PBT durante 10 minutos cada uno

- Bloqueo de la actividad peroxidasa endógena; tratar las preparaciones con peróxido de hidrógeno al 3,5\% durante $30 \mathrm{mi}-$ nutos a temperatura ambiente

- Lavar 2 veces con PBT durante 10 minutos cada uno

- Bloqueo de la actividad botina endógena: tratar las preparaciones con una solución de Avidina durante 15 minutos a 
temperatura ambiente en cámara húmeda. Enjuagar en PBT y aplicar una solución de Biotina durante 15 minutos a temperatura ambiente en cámara húmeda

- Lavar 2 veces con PBT durante 5 minutos cada uno

- Incubación con el anticuerpo secundario, IgG conjugado con Biotina (1:150 en PBT) durante 30 minutos a temperatura ambiente en cámara húmeda. Ver Cuadro 2 para más información.

- Preparación de ABC reagen (10 $\mu \mathrm{l} \mathrm{A}+10 \mu \mathrm{l} \mathrm{BC}+980 \mu \mathrm{l}$ PBT, Vector Laboratories, Burlingame, CA) e incubar 30 minutos a $4{ }^{\circ} \mathrm{C}$ en oscuridad

- Lavar 3 veces en PBT durante 10 minutos cada uno

- Aplicar el ABC reagen a las preparaciones e incubar a 30 minutos a temperatura ambiente en cámara húmeda

- Lavar 2 veces en PBT durante 5 minutos cada uno

- Aplicar solución DAB (1 $\mu$ l peróxido de hidrógeno + $50 \mu \mathrm{l}$ $\mathrm{DAB} 20 \times+950 \mu \mathrm{l}$ PBT) hasta la aparición de color, momento en que se detiene la reacción lavando la preparación con agua destilada

- Contratinción con Hematoxilina unos segundos

- Deshidratar con serie de alcoholes de menor a mayor gradación (unos minutos en cada uno)

- Xileno durante 1 minuto

- Montaje con DePeX y colocación de un cubreobjetos. Dejar solidificar

A continuación se muestran dos tablas resumen de los anticuerpos primarios y secundarios usados para esta técnica, especificándose la fuente y la procedencia de los mismos. 


\begin{tabular}{|c|c|c|c|}
\hline Proteína & Descripción & Fuente del anticuerpo & Procedencia \\
\hline PCNA & $\begin{array}{l}\text { Proteína nu- } \\
\text { clear marcadora } \\
\text { de proliferación } \\
\text { celular }\end{array}$ & $\begin{array}{l}\text { Monoclonal de ratón, } \\
\text { obtenido a partir de la } \\
\text { proteína de la rata }\end{array}$ & $\begin{array}{l}\text { Santa Cruz Bio- } \\
\text { tech. sc- } 56\end{array}$ \\
\hline Cldn11 & $\begin{array}{l}\text { Proteína es- } \\
\text { pecífica de } \\
\text { oligodendrocitos } \\
\text { que forma par- } \\
\text { te de uniones } \\
\text { fuertes }\end{array}$ & $\begin{array}{l}\text { Policlonal de ratón, ob- } \\
\text { tenido a partir de la } \\
\text { proteína humana }\end{array}$ & $\begin{array}{l}\text { Santa Cruz Bio- } \\
\text { tech. sc-25711 } \\
(\mathrm{H}-107)\end{array}$ \\
\hline $\operatorname{PDGFR} \alpha$ & $\begin{array}{l}\text { Receptor alpha } \\
\text { de factor de cre- } \\
\text { cimiento deriva- } \\
\text { do de plaquetas }\end{array}$ & $\begin{array}{l}\text { Policlonal de conejo, } \\
\text { obtenido a partir de la } \\
\text { proteína humana }\end{array}$ & $\begin{array}{l}\text { NeoMarkers ref: } \\
\text { RB-9027 }\end{array}$ \\
\hline $\mathrm{AR}$ & $\begin{array}{l}\text { Receptor de an- } \\
\text { drógenos }\end{array}$ & $\begin{array}{l}\text { Policlonal de conejo, } \\
\text { obtenido a partir de la } \\
\text { proteína humana }\end{array}$ & $\begin{array}{l}\text { Santa Cruz Bio- } \\
\text { tech. sc-815 (C- } \\
\text { 19) }\end{array}$ \\
\hline FoxL2 & $\begin{array}{l}\text { Regulador } \\
\text { transcripcional } \\
\text { de localización } \\
\text { nuclear }\end{array}$ & $\begin{array}{l}\text { Policlonal de conejo, } \\
\text { obtenido a partir de la } \\
\text { proteína humana }\end{array}$ & $\begin{array}{l}\text { Santa Cruz Bio- } \\
\text { tech. } \\
(\mathrm{H}-43)\end{array}$ \\
\hline
\end{tabular}

Cuadro 1: Anticuerpos primarios usados

\begin{tabular}{lllll} 
Anticuerpo & Tipo & Conjugado & Origen & Procedencia \\
\hline Anti-conejo (IgG) & Policlonal & Biotina & Cabra & Vector Labs. Ref. BA-1000 \\
Anti-ratón (IgG) & Policlonal & Biotina & Caballo & Vector Labs. Ref. BA-2000 \\
\hline
\end{tabular}

Cuadro 2: Anticuerpos secundarios usados 


\section{RESULTADOS}

A continuación, se exponen los resultados obtenidos en el estudio del patrón de expresión de los genes PCNA, CLDN11, AR, PDGFR $\alpha$ y FOXL2 en ovoteste de topo durante dos periodos reproductivos distintos: activo (fértil) e inactivo (infértil).

\subsection{PCNA}

La expresión del gen PCNA en la parte ovárica del ovoteste de $T$. occidentalis muestra un patrón parecido entre ambos periodos. En el periodo fértil, se observa una señal fuerte en células de la granulosa y algo más débil en las de la teca, así como señal en el interior de los cuerpos lúteos. Por otro lado, en el periodo infértil, también se observa señal en el interior de los cuerpos lúteos, en células de la granulosa y la teca, en núcleos de oocitos y en folículos primordiales.

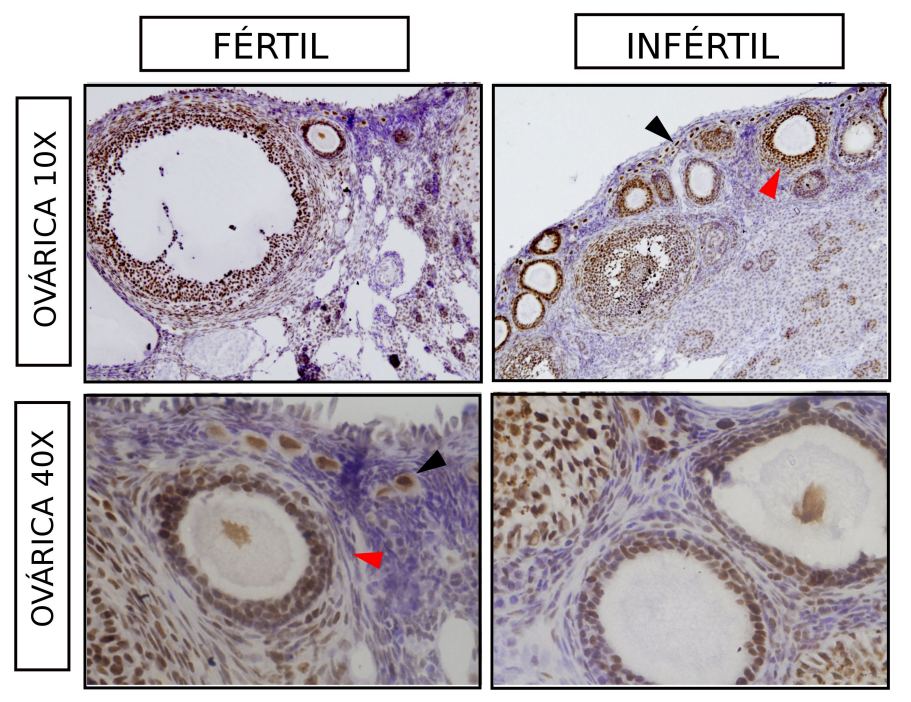

Figura 6: Resultados de expresión de PCNA en parte ovárica: Fértil Imagen a 10 y 40 aumentos de la expresión de PCNA en parte ovárica del ovoteste fértil de $T$. occidentalis. Señal fuerte en células de la granulosa y más débil en células de la teca. Aparece expresión en todos los estadíos de la foliculogénesis. Infértil Imagen a 10 y 40 aumentos de la expresión de PCNA en parte ovárica del ovoteste infértil de T. occidentalis. Patrón de expresión similar al del periodo fértil. Se observan folículos primordiales (flecha negra) y folículos secundarios (flecha roja). 
La expresión del gen PCNA en la parte testicular del ovoteste de $T$. occidentalis muestra una clara diferencia entre los periodos reproductivos activo e inactivo. En el periodo fértil sólo se observa una leve señal inespecífica en células de Leydig, mientras que en el periodo infértil, se puede observar una fuerte expresión en células similares a Sertoli.

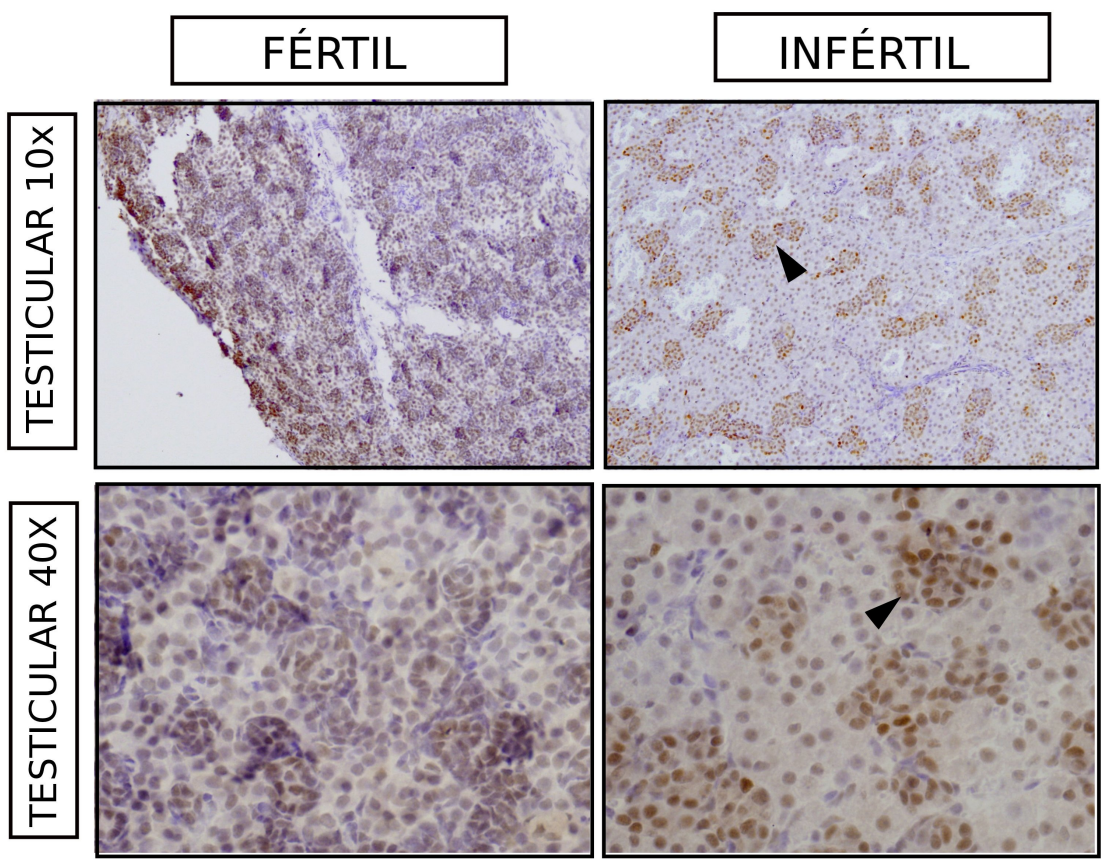

Figura 7: Resultados de expresión de PCNA en parte testicular: Fértil Imagen a 10 y 40 aumentos de la expresión de PCNA en parte testicular del ovoteste fértil de T. occidentalis. Expresión inespecífica en células de Leydig intersticiales. Infértil Imagen a 10 y 40 aumentos de la expresión de PCNA en parte testicular del ovoteste infértil de $T$. occidentalis. Se observa una señal más fuerte en los cordones like-testiculares, por lo que la señal se localiza en las células similares a Sertoli (flecha negra) más que en las intersticiales. 


\subsection{CLDN11}

La expresión del gen CLDN11 en la parte ovárica del ovoteste de T. occidentalis también muestra una gran diferencia entre ambos periodos; en periodo fértil, se observa una señal clara en células de la granulosa, mientras que en periodo infértil, estas células no son inmunorreactivas, y no se observa ningún tipo de señal para este anticuerpo en esta porción.

La expresión del gen CLDN11 en la parte testicular del ovoteste de T. occidentalis se reduce a las uniones fuertes (TJs) entre células de Sertoli. Se puede observar que en el periodo fértil, estas uniones son más compactas (la expresión es más abundante y marcada por señales puntuales fuertes), mientras que en el periodo infértil, las TJs son más laxas, lo que viene indicado por una señal más débil entre las células de similares a Sertoli.

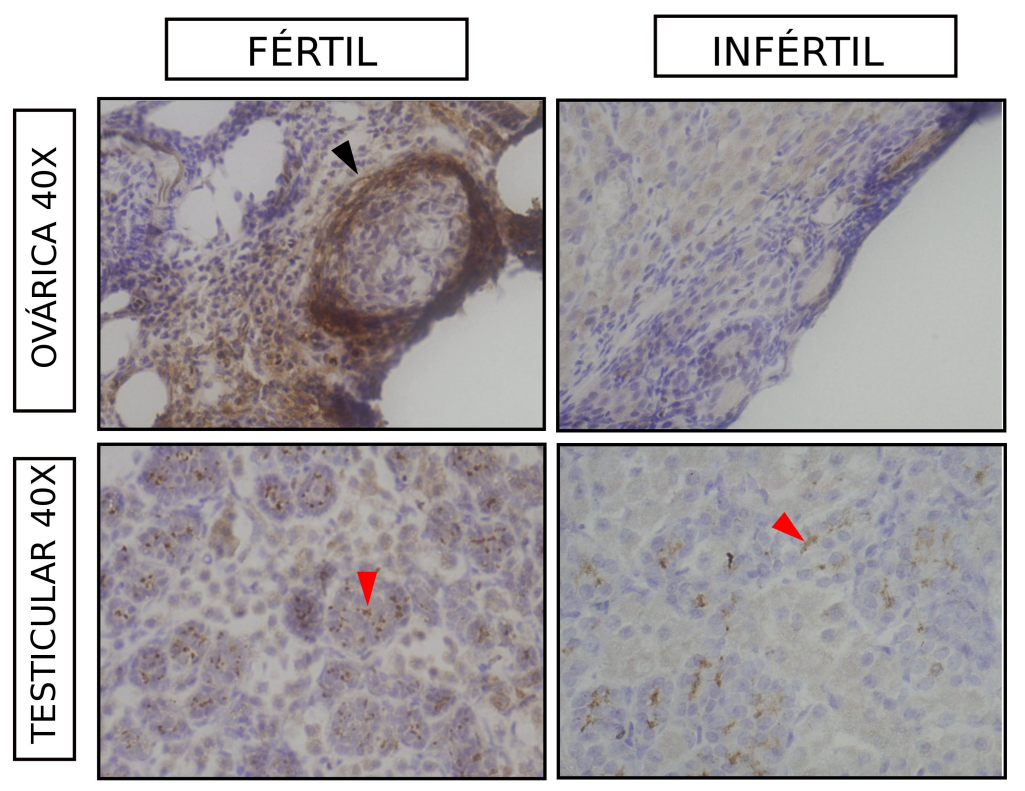

Figura 8: Resultados de expresión de Cldn11 en ovoteste: Parte ovárica Imagen a 40 aumentos que muestra fuerte expresión de la proteína durante el periodo fértil en células de la granulosa (flecha negra), mientras que hay ausencia de señal durante el periodo infértil. Parte testicular Imagen a 40 aumentos que muestra la localización de TJs (flecha roja) durante ambos periodos reproductivos, observándose que hay mayor concentración de éstas durante el periodo fértil. 


\section{3. $\mathbf{A R}$}

La expresión del gen AR en la parte ovárica del ovoteste de T. occidentalis presenta un patrón de expresión similar en ambos periodos reproductivos, observándose una señal fuerte en células de la granulosa y en núcleos de oocitos, mientras que las células de la teca parecen tener menor expresión, estando ésta ausente en los cuerpos lúteos.

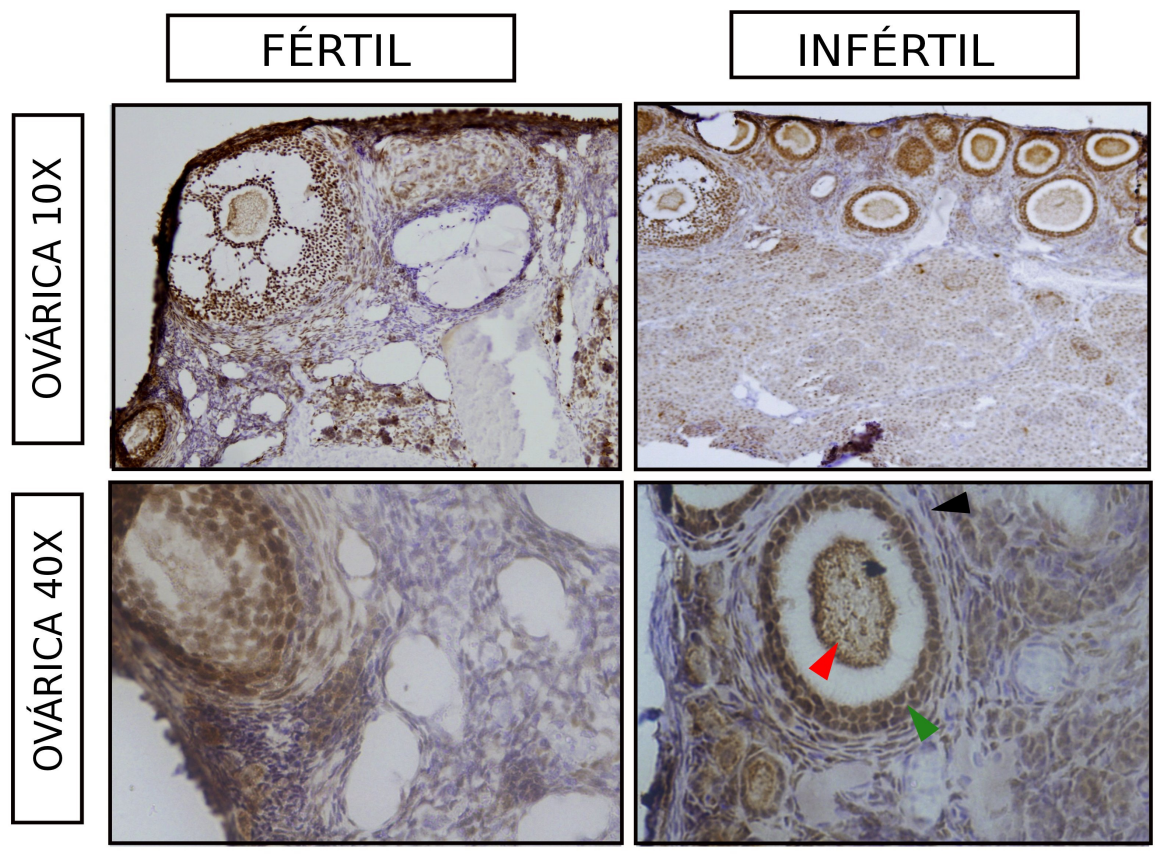

Figura 9: Resultados de expresión de AR en parte ovárica: Fértil Imagen a 10 y 40 aumentos de la expresión de AR en la parte ovárica del ovoteste fértil de $T$. occidentalis. Expresión fuerte en células de la granulosa y núcleos de oocitos. Infértil Imagen a 10 y 40 aumentos de la expresión de AR en la parte ovárica del ovoteste infértil de $T$. occidentalis. Patrón de expresión similar. Se observa ausencia de señal en células de la teca (flecha negra) y presencia en núcleos de oocitos (flecha roja) y células de la granulosa (flecha verde).

La expresión del gen AR en la parte testicular del ovoteste de $T$. occidentalis muestra una clara diferencia entre ambos periodos reproductivos. En el periodo fértil se observa expresión en células de Leydig y no en células similares a Sertoli, mientras que en el periodo infértil no sólo las células de Leydig expresan este receptor, sino también células similares a Sertoli. 


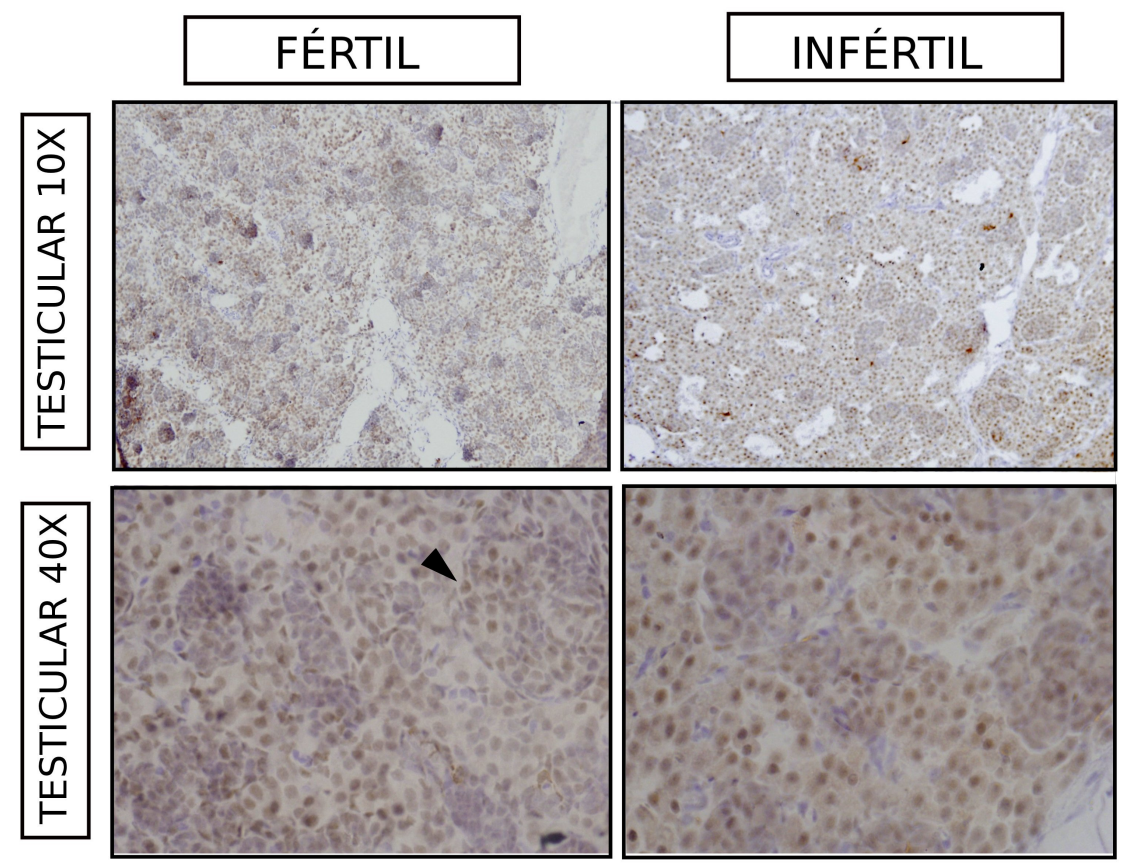

Figura 10: Resultados de expresión de AR en parte testicular: Fértil Imagen a 10 y 40 aumentos de la expresión de AR en la parte testicular del ovoteste fértil de $T$. occidentalis. Expresión en células de Leydig (flecha negra), permaneciendo los cordones like-testiculares carentes de expresión. Infértil Imagen a 10 y 40 aumentos de la expresión de AR en la parte testicular del ovoteste infértil de $T$. occidentalis. Expresión tanto dentro como fuera de los cordones like-testiculares, es decir, señal dentro de células de Leydig y de células similares a Sertoli. 


\subsection{PDGFR $\alpha$}

La expresión del gen PDGFR $\alpha$ en la parte ovárica del ovoteste de T. occidentalis parece reducirse al interior de los cuerpos lúteos en el periodo fértil, mientras que células de la granulosa, la teca y oocitos no presentan expresión en ninguno de los periodos reproductivos.

La expresión del gen PDGFR $\alpha$ en la parte testicular del ovoteste de T. occidentalis no muestra una diferencia en cuanto a patrón, ya que en ambos periodos podemos observar una señal en células endoteliales de los vasos sanguíneos, y ausencia de expresión en células de Leydig y similares a Sertoli.

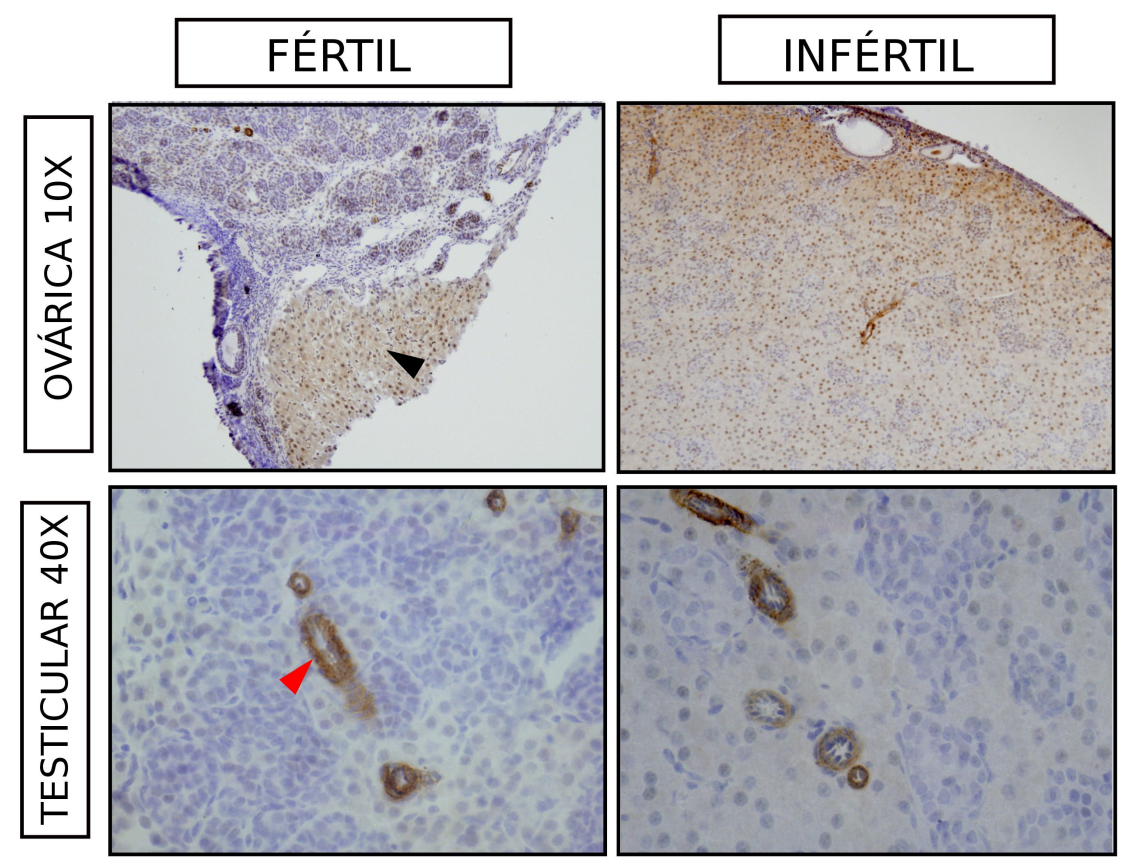

Figura 11: Resultados de expresión de PDGFR $\alpha$ en ovoteste: Parte ovárica Imagen a 10 aumentos que muestra acumulación de señal en el interior de cuerpos lúteos (flecha negra) y núcleos de oocitos pero que parece ser una señal inespecífica. Parte testicular Imagen a 40 aumentos que muestra señal sólo en torno a los vasos sanguíneos, pareciendo asociada al endotelio (flecha roja). 


\subsection{FOXL2}

La expresión del gen FoxL2 en la parte ovárica del ovoteste de $T$. occidentalis presenta un patrón parecido en ambos periodos reproductivos, observándose una señal fuerte en células de la granulosa de folículos primarios, que va desapareciendo al ir madurando éstos, y desaparece en folículos secundarios. Células de la teca, cuerpos lúteos y oocitos no presentan expresión en periodo infértil, pero sin embargo, células de la teca si presentan señal en periodo fértil.

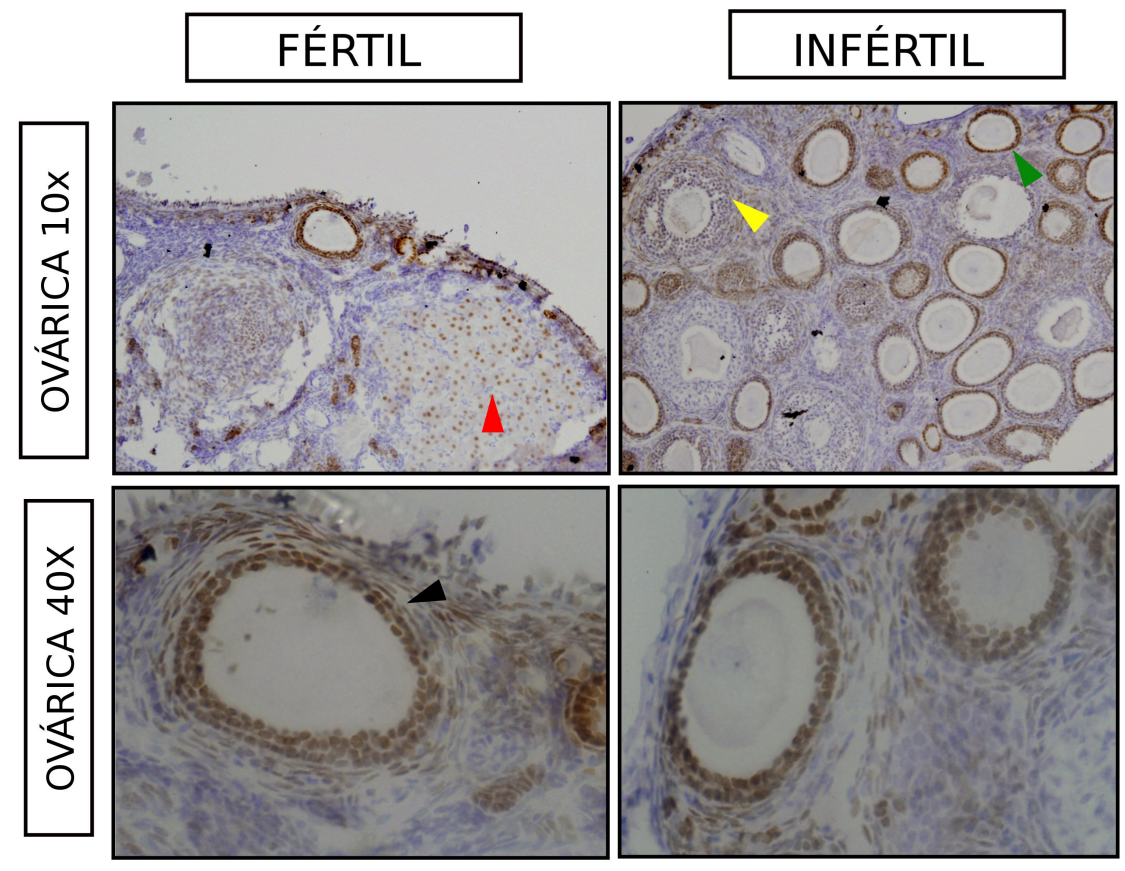

Figura 12: Resultados de expresión de FoxL2 en parte ovárica: Fértil Imagen a 10 y 40 aumentos de la expresión de FoxL2 en la parte ovárica del ovoteste fértil de $T$. occidentalis. Expresión en células de la granulosa y de la teca (flecha negra), así como en el interior de cuerpos lúteos (flecha roja). Infértil Imagen a 10 y 40 aumentos de la expresión de FoxL2 en la parte ovárica del ovoteste infértil de $T$. occidentalis. Señal fuerte en células de la granulosa que va desapareciendo al ir madurando los folículos. Folículo primario (flecha verde), folículo secundario (flecha amarilla). Células de la teca sin expresión.

La expresión del gen FoxL2 en la parte testicular del ovoteste de $T$. occidentalis también muestra un patrón semejante en los dos periodos, si bien, la expresión parece ser algo mayor en el periodo fértil (teniendo 
en cuenta que este método es semicuantitativo). La expresión en ambos casos se reduce a células similares a Sertoli, permaneciendo las células de Leydig sin señal.

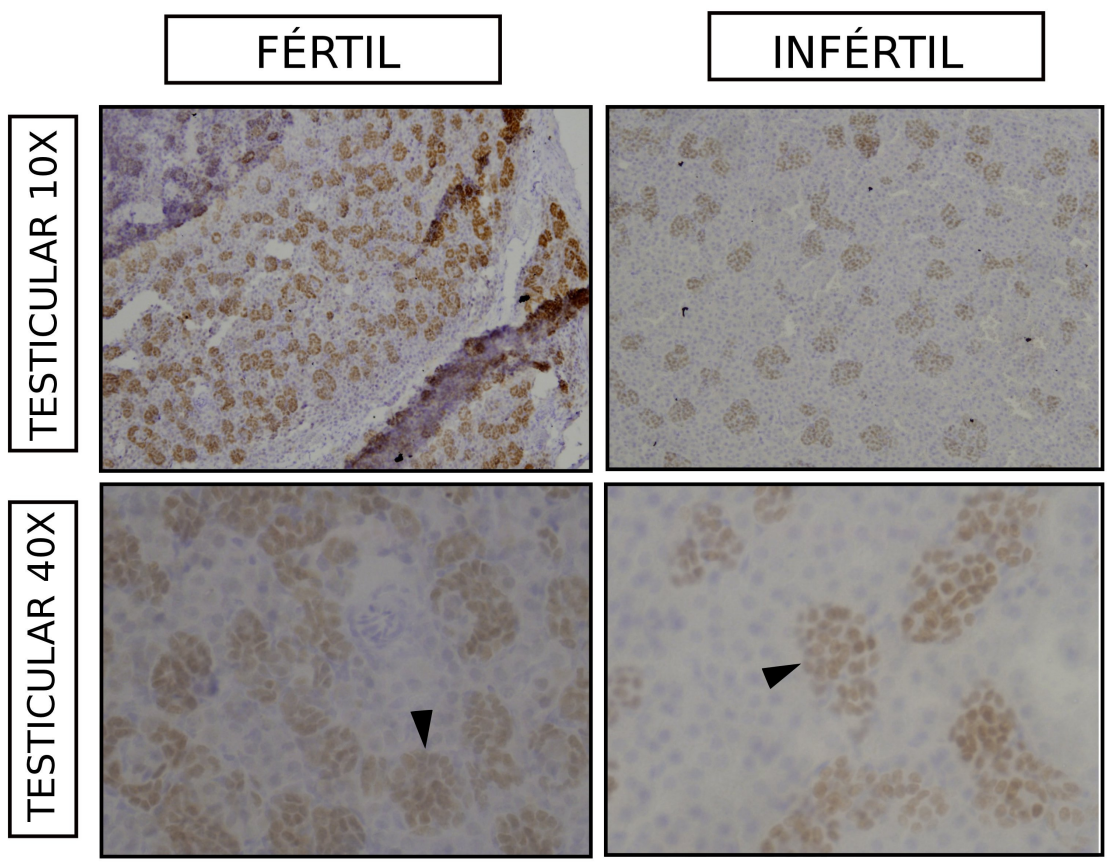

Figura 13: Resultados de expresión de FoxL2 en parte testicular: Fértil Imagen a 10 y 40 aumentos de la expresión de FoxL2 en la parte testicular del ovoteste fértil de $T$. occidentalis. Se observa expresión en células similares a Sertoli que forman los cordones like-testiculares (flecha negra). Infértil Imagen a 10 y 40 aumentos de la expresión de FoxL2 en la parte testicular del ovoteste infértil de $T$. occidentalis. Patrón de expresión semejante al periodo fértil, aunque la densidad de expresión parece ser menor. 


\section{DISCUSION}

En este trabajo hemos analizado la expresión de 5 genes que pueden tener un papel importante en el control del ciclo estacional reproductivo de T. occidentalis. A continuación, pasamos a discutir cada uno de los genes estudiados.

\subsection{PCNA}

PCNA es un marcador utilizado para estudios de proliferación celular (Kurki et al., 1988), lo que implica que juega un papel importante en muchos procesos del desarrollo embrionario. Debido a ello, nos preguntamos si este gen puede estar implicado también en el control de los cambios estacionales que tienen lugar en el ovoteste de T. occidentalis.

En primer lugar, analizaremos la parte ovárica. Según lo descrito por Chapman y Wolgemuth (1994) en ovario, PCNA se expresa en oocitos de folículos en crecimiento y en células de la granulosa del mismo tipo celular. Estos autores no describieron expresión de PCNA en oocitos de folículos primordiales. Nuestros estudios de expresión de PCNA en la parte ovárica de ovoteste de T. occidentalis en periodo fértil coinciden con los de Chapman y Wolgemuth (1994), pero además, nosotros hemos encontrado una fuerte expresión de PCNA en oocitos pertenecientes a folículos primordiales, resultado que no coincide con el de los autores anteriores. En periodo infértil nuestros resultados de expresión coinciden con los del periodo fértil. Esto implica que PCNA puede tener una función conservada en la fase proliferativa de la foliculogénesis. Teniendo en cuenta que, en otros tejidos, la función principal de PCNA es ayudar a la DNA polimerasa en la replicación y reparación del DNA, es concebible pensar que tiene la misma función en este tejido. Dado que no hemos encontrado diferencias en el patrón de expresión de PCNA entre tejido ovárico de ovoteste en periodo fértil e infértil, podemos concluir que este gen no está implicado en la regulación estacional de la reproducción de $T$. occidentalis.

En segundo lugar, analizaremos la parte testicular. En este caso, la comparación con estudios previos es más difícil, ya que en éstos, la expresión suele aparecer en espermatocitos en crecimiento (que son las células que mayor actividad proliferativa tienen en ese momento), y en nuestro caso, puesto que la porción testicular del ovoteste es un tejido disgenésico, sin células germinales, no podemos observar esta expresión. Sin embargo, sí observamos diferencias entre ambos periodos reproductivos. La ausencia de expresión de PCNA durante el periodo fér- 
til, puede indicar que la porción testicular está más inactiva (hablando desde un punto de vista proliferativo) que esta misma porción durante el periodo infértil, que sí presenta una clara expresión en células similares a Sertoli. En periodo inactivo, la porción testicular aumenta su actividad metabólica (aumento de tamaño, producción de testosterona), por lo que la expresión de PCNA en células similares a Sertoli en esta época puede estar implicada en el control de este aumento en la actividad metabólica. Estudios encaminados a dilucidar el papel del gen durante este proceso se están llevando a cabo actualmente en nuestro laboratorio.

\subsection{CLDN11}

Se sabe que CLDN11, junto con otras claudinas y ocludinas, forman un conjunto de proteínas de adhesión implicadas, entre otras uniones fuertes, en las TJs (Morrow et al., 2010). Ejemplos de estas TJs se forman entre células de Sertoli en testículo, para formar la barrera hematotesticular (Mruk y Cheng, 2004) mientras que no se ha descrito su expresión en ovarios. También se ha demostrado que altas concentraciones de testosterona aumentan de forma significativa, entre dos y tres veces, la formación de estas TJs in vitro (Kaitu'u-Lino et al., 2007), aunque in vivo parecen actuar también otros factores.

En primer lugar, analizaremos la parte ovárica. Aquí hemos observado una clara diferencia de expresión entre periodo fértil e infértil, observándose una señal fuerte en folículos de ovoteste activo, que desaparece en inactivos. Esto nos hace pensar que la presencia de esta proteína en folículos puede contribuir a su activación, pudiendo verse implicada algún tipo de unión celular entre células de la granulosa hasta ahora no descrita.

En segundo lugar, analizaremos la parte testicular. La expresión en esta porción sigue un patrón parecido al que se encuentra formando la barrera hematotesticular ya que se presentan entre células similares a Sertoli, de manera homóloga a lo que ocurre entre células de Sertoli. En este caso, la existencia de esta barrera no tendría la misma función, ya que no sería necesaria la formación de este microambiente (porque no se produce maduración de las células germinales). Observamos diferencias entre ambos periodos reproductivos, ya que en periodo fértil la expresión es más abundante que en periodo infértil. No obstante, los datos no son concluyentes debido a que hay variabilidad interindividual en el tejido testicular de ovoteste y solo hemos estudiado una hembra. Además hay que tener en cuenta que la hembra que hemos es- 
tudiado estaba preñada, por lo que sería necesario estudiar cómo está el tejido en hembra estro (adulta y fértil) en varios individuos.

\section{3. $\mathbf{A R}$}

Se sabe que AR es un receptor, que en ratones se expresa en células de Leydig, mioides y de Sertoli (Zhou et al., 2002) y cuyo ligando son hormonas esteroideas (andrógenos) responsables de la expresión fenotípica de macho.

En primer lugar, analizaremos la parte ovárica. Previamente se ha descrito en primates la expresión de AR en ovario y se ha encontrado expresión en células de la granulosa (Hillier et al., 1997). Nuestros estudios de expresión de AR en la parte ovárica de ovoteste de T. occidentalis en periodo fértil coinciden con los de Hillier et al. (1997), pero además, nosotros hemos encontrado expresión de AR en oocitos pertenecientes a folículos primordiales, un resultado no descrito previamente. En periodo infértil nuestros resultados de expresión coinciden con los del periodo fértil. Estos resultados implican que en ovoteste de $T$. occidentalis, tanto en época fertil como infértil, los andrógenos tienen un papel importante en la regulación de la foliculogénesis.

En segundo lugar, analizaremos la parte testicular. Puesto que el ligando de este receptor es la testosterona, y sabiendo que en el periodo infértil es donde mayor abundancia hay de esta hormona, cabe pensar que es en este periodo en el que nos encontraremos mayor expresión de AR. De hecho, observando los resultados, confirmamos que esto es así, ya que en periodo infértil se expresa tanto en células similares a Sertoli como en células de Leydig, mientras que en periodo fértil sólo se expresa en estas últimas.

\subsection{PDGFR $\alpha$}

Se sabe que en respuesta a PDGFR $\alpha$, se produce proliferación y migración de las células mesenquimáticas, lo que contribuye a la morfogénesis e integridad de diversos órganos (Hoch y Soriano, 2003). Con el estudio de expresión de este gen, nos planteamos si también tiene implicaciones en los procesos de cambio estacionales que se producen en la gónada femenina de T. occidentalis.

En primer lugar, analizaremos la parte ovárica. Aunque observamos señal en el interior de los cuerpos lúteos y en núcleos de oocitos, esta señal parece ser inespecífica, no detectándose expresión en células de 
la granulosa o de la teca de los folículos en ninguno de los periodos reproductivos. Esto nos lleva a pensar que este gen parece no ejercer ningún papel fundamental en el proceso de la foliculogénesis.

En segundo lugar, analizaremos la parte testicular. En ambos periodos observamos una fuerte expresión en células endoteliales, al igual que ocurre en la parte ovárica, lo que corrobora su función en endotelios, y, de la misma manera que en el caso anterior, nos hace pensar que este gen tampoco ejerce un papel fundamental en la secreción de hormonas esteroideas.

\subsection{FOXL2}

Se sabe que FoxL2 está implicado en el desarrollo ovárico (Crisponi et al., 2001; Schmidt et al., 2004), ya que ratones knock-out para FoxL2 han demostrado que este gen es necesario para la maduración de los folículos (Uda et al., 2004). Además, su expresión es necesaria para que se regule correctamente la secreción de gonadotropinas (Ellsworth et al., 2003, 2006). Por ello, su estudio en ovoteste de T. occidentalis puede ser interesante para comprobar su función tanto en uno como en otro proceso.

En primer lugar, analizaremos la parte ovárica. Aunque apenas observamos diferencias entre ambos periodos reproductivos, podemos destacar la desaparición de la señal en células de la granulosa a medida que éstas van madurando. Esta expresión diferencial puede ser indicativa de que este gen está implicado en la maduración de la foliculogénesis, lo que es consistente con el papel conocido de FoxL2 descrito por Uda et al. (2004).

En segundo lugar, analizaremos la parte testicular. En los dos periodos reproductivos observamos expresión del gen, con un patrón similar, apareciendo señal en las células similares a Sertoli, aunque parece que la expresión es mayor durante la época fértil. La mayor presencia de expresión de este gen en la porción testicular durante el periodo fértil puede ser indicativa de que FoxL2 es necesario para controlar alguna de las funciones propias de ésta época. No obstante, habría que comprobar mediante qPCR que esta diferencia entre periodos sea real.

\section{CONCLUSIONES}

A la vista de los resultados que hemos obtenido en esta investigación y que se han mostrado en este Trabajo Fin de Máster, pasamos a 
enumerar las conclusiones más importantes, que relacionaremos con la función que nosotros planteamos para cada una de las proteínas estudiadas durante el ciclo estacional reproductivo de $T$. occidentalis.

- Nuestros resultados en topo indican que PCNA tiene un papel conservado en la fase proliferativa de la foliculogénesis.

- La expresión de PCNA en la porción testicular del ovoteste indica que hay mayor actividad metabólica en células similares a Sertoli durante el periodo infértil.

- Algún tipo de unión fuerte mediada por CLDN11 en la parte ovárica del ovoteste no descrita hasta ahora, puede estar implicada en la maduración folicular.

- El gen AR en la porción ovárica parece ser necesario para la regulación de la foliculogénesis, pero no interviene en el control estacional ya que no se observan diferencias en los patrones de expresión entre los periodos reproductivos.

- El aumento de expresión de AR en la parte testicular del ovoteste en periodo inactivo es coherente con el aumento de testosterona circulante que los topos poseen en este periodo.

- PDGFR $\alpha$ parece no ejercer ningún papel en los cambios estacionales producidos en la gónada femenina de T. occidentalis, ni en la porción ovárica ni en la testicular.

- Nuestros resultados obtenidos en topo indican que FoxL2 juega un papel conservado durante la foliculogénesis . 


\section{Referencias}

Arendt J. (1995) Melatonin and the Mammalian Pineal Gland. Chapman \& Hall.

Beery A.K., Trumbull J.J., Tsao J.M., Costantini R.M. y Zucker I. (2007) Sex differences in the onset of seasonal reproductive quiescence in hamsters. Proc Biol Sci, 274:281-286.

Bergmann M. (1987) Photoperiod and testicular function in phodopus sungorus. Adv Anat Embryol Cell Biol, 105:1-76.

Bousfield G.R. y Dias J.A. (2011) Synthesis and secretion of gonadotropins including structure-function correlates. Rev Endocr Metab Disord.

Bravo R. y Macdonald-Bravo H. (1987) Existence of two populations of cyclin/proliferating cell nuclear antigen during the cell cycle: association with dna replication sites. $J$ Cell Biol, 105:1549-1554.

Brennan J., Tilmann C. y Capel B. (2003) Pdgfr-alpha mediates testis cord organization and fetal leydig cell development in the xy gonad. Genes Dev, 17:800-810.

Bronson F. (1989) Mammalian Reproductive Biology. Univ. Chicago Press.

Bronson F. y Heideman P. (1994) Seasonal regulation of reproduction in mammals. The Physiology of Reproduction. 2nd Edition. New York, Raven Press 2:541-584.

Bronson F.H. (1985) Mammalian reproduction: an ecological perspective. Biol Reprod, 32:1-26.

Bronson F.H. (2009) Climate change and seasonal reproduction in mammals. Philos Trans $R$ Soc Lond B Biol Sci, 364:3331-3340.
Bronstein J.M., Popper P., Micevych P.E. y Farber D.B. (1996) Isolation and characterization of a novel oligodendrocyte-specific protein. $\mathrm{Neu}$ rology, 47:772-778.

Cabrera A. (1914) Fauna ibérica: mamíferos.

Cárdenas H. y Pope W.F. (2002) Androgen receptor and follicle-stimulating hormone receptor in the pig ovary during the follicular phase of the estrous cycle. Mol Reprod Dev, 62:92-98.

Carmona F.D., Lupiáñez D.G., Real F.M., Burgos M., Zurita F. y Jiménez R. (2009) The spatio-temporal pattern of testis organogenesis in mammals - insights from the mole. Int $J$ Dev Biol, 53:1035-1044.

Carmona F.D., Motokawa M., Tokita M., Tsuchiya K., Jiménez R. y SánchezVillagra M.R. (2008) The evolution of female mole ovotestes evidences high plasticity of mammalian gonad development. J Exp Zool B Mol Dev Evol, 310:259-266.

Chadha S., Pache T.D., Huikeshoven J.M., Brinkmann A.O. y van der Kwast T.H. (1994) Androgen receptor expression in human ovarian and uterine tissue of long-term androgen-treated transsexual women. Hum Pathol, 25:1198-1204.

Chang C.S., Kokontis J. y Liao S.T. (1988) Molecular cloning of human and rat complementary dna encoding androgen receptors. Science, 240:324-326.

Chapman D.L. y Wolgemuth D.J. (1994) Expression of proliferating cell nuclear antigen in the mouse germ line and surrounding somatic cells suggests both proliferation-dependent and -independent modes of function. Int $J$ Dev Biol, 38:491-497. 
Chieffi P., Nasti M., Fulgione D. y Franco R. (2001) Expression of pcna in the testis of the lizard, podarcis s. sicula: an endogenous molecular marker of mitotic germinal epithelium proliferation. Zygote, 9:317-322.

Clarke I.J. y Pompolo S. (2005) Synthesis and secretion of gnrh. Anim Reprod Sci, 88:29-55.

Crisponi L., Deiana M., Loi A., Chiappe F., Uda M., Amati P., Bisceglia L., Zelante L., Nagaraja R., Porcu S., Ristaldi M.S., Marzella R., Rocchi M., Nicolino M., Lienhardt-Roussie A., Nivelon A., Verloes A., Schlessinger D., Gasparini P., Bonneau D., Cao A. y Pilia G. (2001) The putative forkhead transcription factor foxl2 is mutated in blepharophimosis/ptosis/epicanthus inversus syndrome. Nat Genet, 27:159-166.

Dadhich R.K., Real F.M., Zurita F., Barrionuevo F.J., Burgos M. y Jiménez R. (2010) Role of apoptosis and cell proliferation in the testicular dynamics of seasonal breeding mammals: a study in the iberian mole, talpa occidentalis. Biol Reprod, 83:83-91.

Ellsworth B.S., Burns A.T., Escudero K.W., Duval D.L., Nelson S.E. y Clay C.M. (2003) The gonadotropin releasing hormone (gnrh) receptor activating sequence (gras) is a composite regulatory element that interacts with multiple classes of transcription factors including smads, ap-1 and a forkhead dna binding protein. Mol Cell Endocrinol, 206:93-111.

Ellsworth B.S., Egashira N., Haller J.L., Butts D.L., Cocquet J., Clay C.M., Osamura R.Y. y Camper S.A. (2006) Foxl2 in the pituitary: molecular, genetic, and developmental analysis. Mol Endocrinol, 20:2796-2805.

Eriksson A., Siegbahn A., Westermark B., Heldin C.H. y Claesson-Welsh L.
(1992) Pdgf alpha- and beta-receptors activate unique and common signal transduction pathways. EMBO J, 11:543-550.

Florin A., Maire M., Bozec A., Hellani A., Chater S., Bars R., Chuzel F. y Benahmed M. (2005) Androgens and postmeiotic germ cells regulate claudin- 11 expression in rat sertoli cells. Endocrinology, 146:1532-1540.

Gilling-Smith C., Willis D.S., Beard R.W. y Franks S. (1994) Hypersecretion of androstenedione by isolated thecal cells from polycystic ovaries. J Clin Endocrinol Metab, 79:1158-1165.

Gnessi L., Emidi A., Jannini E.A., Carosa E., Maroder M., Arizzi M., Ulisse S. y Spera G. (1995) Testicular development involves the spatiotemporal control of pdgfs and pdgf receptors gene expression and action. J Cell Biol, 131:1105-1121.

Goodman R.L. (1994) Neuroendorine control of the ovine estrous cycle. In: The Physiology of Reproduction. Raven, New York.

Govoroun M.S., Pannetier M., Pailhoux E., Cocquet J., Brillard J., Couty I., Batellier F. y Cotinot C. (2004) Isolation of chicken homolog of the foxl2 gene and comparison of its expression patterns with those of aromatase during ovarian development. Dev Dyn, 231:859870 .

Griffin J.E. (1992) Androgen resistancethe clinical and molecular spectrum. $N$ Engl J Med, 326:611-618.

Gye M.C. (2003) Changes in the expression of claudins and transepithelial electrical resistance of mouse sertoli cells by leydig cell coculture. Int J Androl, 26:271-278. 
Hampton J.H., Manikkam M., Lubahn D.B., Smith M.F. y Garverick H.A. (2004) Androgen receptor mrna expression in the bovine ovary. Domest Anim Endocrinol, 27:81-88.

Heinlein C.A. y Chang C. (2002) Androgen receptor (ar) coregulators: an overview. Endocr Rev, 23:175-200.

Heldin C.y.B.W. (1996) Role of PlateletDerived Growth Facto In Vivo (2nd ed). New York: Plenum.

Hellani A., Ji J., Mauduit C., Deschildre C., Tabone E. y Benahmed M. (2000) Developmental and hormonal regulation of the expression of oligodendrocyte-specific protein/claudin 11 in mouse testis. Endocrinology, 141:3012-3019.

Hillier S.G., Tetsuka M. y Fraser H.M. (1997) Location and developmental regulation of androgen receptor in primate ovary. Hum Reprod, 12:107-111.

Hirai M., Hirata S., Osada T., Hagihara K. y Kato J. (1994) Androgen receptor mrna in the rat ovary and uterus. $J$ Steroid Biochem Mol Biol, 49:1-7.

Hoch R.V. y Soriano P. (2003) Roles of pdgf in animal development. Development, 130:4769-4784.

Holdcraft R.W. y Braun R.E. (2004) Androgen receptor function is required in sertoli cells for the terminal differentiation of haploid spermatids. Development, 131:459-467.

Horie K., Takakura K., Fujiwara H., Suginami H., Liao S. y Mori T. (1992) Immunohistochemical localization of androgen receptor in the human ovary throughout the menstrual cycle in relation to oestrogen and progesterone receptor expression. Hum Reprod, 7:184-190.
Hossain M.Z., Ao P. y Boynton A.L. (1998) Rapid disruption of gap junctional communication and phosphorylation of connexin 43 by platelet-derived growth factor in t51b rat liver epithelial cells expressing platelet-derived growth factor receptor. J Cell Physiol, 174:66-77.

Hu Y.C., Wang P.H., Yeh S., Wang R.S., Xie C., Xu Q., Zhou X., Chao H.T., Tsai M.Y. y Chang C. (2004) Subfertility and defective folliculogenesis in female mice lacking androgen receptor. Proc Natl Acad Sci U S A, 101:1120911214.

Jimenez R., Burgos M., Sanchez A. y de la Guardia R.D. (1990) The reproductive cycle of talpa occidentalis in teh southeastern iberian peninsula. Act Ther, 35:165-169.

Jiménez R., Burgos M., Sánchez A., Sinclair A.H., Alarcón F.J., Marín J.J., Ortega E. y de la Guardia R.D. (1993) Fertile females of the mole talpa occidentalis are phenotypic intersexes with ovotestes. Development, 118:13031311.

Juengel J.L., Heath D.A., Quirke L.D. y McNatty K.P. (2006) Oestrogen receptor alpha and beta, androgen receptor and progesterone receptor mrna and protein localisation within the developing ovary and in small growing follicles of sheep. Reproduction, 131:8192.

Kaitu'u-Lino T.J., Sluka P., Foo C.F.H. y Stanton P.G. (2007) Claudin-11 expression and localisation is regulated by androgens in rat sertoli cells in vitro. Reproduction, 133:1169-1179.

Kaplan D.R., Chao F.C., Stiles C.D., Antoniades H.N. y Scher C.D. (1979) Platelet alpha granules contain a growth factor for fibroblasts. Blood, 53:10431052. 
Kurki P., Ogata K. y Tan E.M. (1988) Monoclonal antibodies to proliferating cell nuclear antigen (pcna)/cyclin as probes for proliferating cells by immunofluorescence microscopy and flow cytometry. J Immunol Methods, 109:4959 .

Loffler K.A., Zarkower D. y Koopman P. (2003) Etiology of ovarian failure in blepharophimosis ptosis epicanthus inversus syndrome: Foxl2 is a conserved, early-acting gene in vertebrate ovarian development. Endocrinology, 144:3237-3243.

Lubahn D.B., Joseph D.R., Sullivan P.M., Willard H.F., French F.S. y Wilson E.M. (1988) Cloning of human androgen receptor complementary dna and localization to the $\mathrm{x}$ chromosome. Science, 240:327-330.

Madsen P. y Celis J.E. (1985) S-phase patterns of cyclin (pcna) antigen staining resemble topographical patterns of dna synthesis. a role for cyclin in dna replication? FEBS Lett, 193:5-11.

Malpaux B., Migaud M., Tricoire H. y Chemineau P. (2001) Biology of mammalian photoperiodism and the critical role of the pineal gland and melatonin. J Biol Rhythms, 16:336-347.

Mathews L. (1935) The oestrous cycle and intersexuality in teh female mole (talpa europaea linn). Proc Zool Soc Lond, 2:347-83.

McPhaul M.J. (1999) Molecular defects of the androgen receptor. J Steroid Biochem Mol Biol, 69:315-322.

Moffatt C.A., DeVries A.C. y Nelson R.J. (1993) Winter adaptations of male deer mice (peromyscus maniculatus) and prairie voles (microtus ochrogaster) that vary in reproductive responsiveness to photoperiod. J Biol Rhythms, 8:221-232.
Moffatt-Blue C.S., Sury J.J. y Young K.A. (2006) Short photoperiod-induced ovarian regression is mediated by apoptosis in siberian hamsters (phodopus sungorus). Reproduction, 131:771782 .

Morrow C.M.K., Mruk D., Cheng C.Y. y Hess R.A. (2010) Claudin and occludin expression and function in the seminiferous epithelium. Philos Trans $R$ Soc Lond B Biol Sci, 365:1679-1696.

Mossman H.D.K. (1973) Comparative morphology of the mammalian ovary. Madison, University of Wisconsin Press.

Mruk D.D. y Cheng C.Y. (2004) Sertolisertoli and sertoli-germ cell interactions and their significance in germ cell movement in the seminiferous epithelium during spermatogenesis. Endocr Rev, 25:747-806.

Neuwald J.L. y Valenzuela N. (2011) The lesser known challenge of climate change: thermal variance and sex-reversal in vertebrates with temperature-dependent sex determination. PLoS One, 6:e18117.

Oakley A.E., Clifton D.K. y Steiner R.A. (2009) Kisspeptin signaling in the brain. Endocr Rev, 30:713-743.

Oktay K., Schenken R.S. y Nelson J.F. (1995) Proliferating cell nuclear antigen marks the initiation of follicular growth in the rat. Biol Reprod, 53:295301.

PEYRE A. (1962) [research on specific intersexuality in galemys pyrenaicus, g. (mammalia, insectivora)]. Arch Biol (Liege), 73:1-174.

Pinkas H., Fisch B., Rozansky G., Felz C., Kessler-Icekson G., Krissi H., Nitke S., Ao A. y Abir R. (2008) Plateletderived growth factors (pdgf-a and b) and their receptors in human fetal 
and adult ovaries. Mol Hum Reprod, 14:199-206.

Popoff N. (1911) Le tissue interstitiel et les corps jaunes de l'ovarie. Arch Biol Paris, 26:483-48.

Prelich G., Kostura M., Marshak D.R., Mathews M.B. y Stillman B. (1987) The cell-cycle regulated proliferating cell nuclear antigen is required for sv40 dna replication in vitro. Nature, 326:471-475.

Quigley C.A., Bellis A.D., Marschke K.B., el Awady M.K., Wilson E.M. y French F.S. (1995) Androgen receptor defects: historical, clinical, and molecular perspectives. Endocr Rev, 16:271-321.

Raines E. W. D.F.B.P. y Ross R. (1990) Platelet-Derived Growth Factor. Heidelberg: Springer-Verlag.

Revel F.G., Saboureau M., Masson-Pévet M., Pévet P., Mikkelsen J.D. y Simonneaux V. (2006) Kisspeptin mediates the photoperiodic control of reproduction in hamsters. Curr Biol, 16:17301735 .

Ricci G., Catizone A. y Galdieri M. (2004) Embryonic mouse testis development: role of platelet derived growth factor (pdgf-bb). J Cell Physiol, 200:458-467.

Robinson J.E. y Karsch F.J. (1988) Timing the breeding season of the ewe: what is the role of daylength? Reprod Nutr Dev, 28:365-374.

Ross R., Glomset J., Kariya B. y Raines E. (1978) Role of platelet factors in the growth of cells in culture. Natl Cancer Inst Monogr, pp. 103-108.

Rubenstein N.M., Cunha G.R., Wang Y.Z., Campbell K.L., Conley A.J., Catania K.C., Glickman S.E. y Place N.J. (2003) Variation in ovarian morphology in four species of new world moles with a peniform clitoris. Reproduction, 126:713-719.

Sánchez A., Bullejos M., Burgos M., Hera C., Stamatopoulos C., la Guardia R.D.D. y Jiménez R. (1996) Females of four mole species of genus talpa (insectivora, mammalia) are true hermaphrodites with ovotestes. Mol Reprod Dev, 44:289-294.

Schmidt D., Ovitt C.E., Anlag K., Fehsenfeld S., Gredsted L., Treier A.C. y Treier M. (2004) The murine wingedhelix transcription factor foxl2 is required for granulosa cell differentiation and ovary maintenance. Development, 131:933-942.

Sen A. y Hammes S.R. (2010) Granulosa cell-specific androgen receptors are critical regulators of ovarian development and function. Mol Endocrinol, 24:1393-1403.

Shure D., Senior R.M., Griffin G.L. y Deuel T.F. (1992) Pdgf aa homodimers are potent chemoattractants for fibroblasts and neutrophils, and for monocytes activated by lymphocytes or cytokines. Biochem Biophys Res Commun, 186:1510-1514.

Sisk C.L. y Foster D.L. (2004) The neural basis of puberty and adolescence. Nat Neurosci, 7:1040-1047.

Słomczyńska M., Duda M. y Ślęzak K. (2001) The expression of androgen receptor, cytochrome p450 aromatase and fsh receptor mrna in the porcine ovary. Folia Histochem Cytobiol, 39:913.

Smith C.A., McClive P.J., Hudson Q. y Sinclair A.H. (2005) Male-specific cell migration into the developing gonad is a conserved process involving pdgf signalling. Dev Biol, 284:337-350. 
Spada A.R.L., Wilson E.M., Lubahn D.B., Harding A.E. y Fischbeck K.H. (1991) Androgen receptor gene mutations in $\mathrm{x}$-linked spinal and bulbar muscular atrophy. Nature, 352:77-79.

Suzuki T., Sasano H., Kimura N., Tamura M., Fukaya T., Yajima A. y Nagura H. (1994) Immunohistochemical distribution of progesterone, androgen and oestrogen receptors in the human ovary during the menstrual cycle: relationship to expression of steroidogenic enzymes. Hum Reprod, 9:1589-1595.

Szołtys M. y Słomczyńska M. (2000) Changes in distribution of androgen receptor during maturation of rat ovarian follicles. Exp Clin Endocrinol Diabetes, 108:228-234.

Tetsuka M. y Hillier S.G. (1996) Androgen receptor gene expression in rat granulosa cells: the role of folliclestimulating hormone and steroid hormones. Endocrinology, 137:43924397.

Tománek M. y Chronowska E. (2006) Immunohistochemical localization of proliferating cell nuclear antigen (pcna) in the pig ovary. Folia Histochem Cytobiol, 44:269-274.

Trainor B.C., Finy M.S. y Nelson R.J. (2008) Rapid effects of estradiol on male aggression depend on photoperiod in reproductively non-responsive mice. Horm Behav, 53:192-199.

Trainor B.C., Rowland M.R. y Nelson R.J. (2007) Photoperiod affects estrogen receptor alpha, estrogen receptor beta and aggressive behavior. Eur $J \mathrm{Neu}$ rosci, 26:207-218.

Uda M., Ottolenghi C., Crisponi L., Garcia J.E., Deiana M., Kimber W., Forabosco A., Cao A., Schlessinger D. y Pilia G. (2004) Foxl2 disruption causes mouse ovarian failure by pervasive blockage of follicle development. Hum Mol Genet, 13:1171-1181.

Vrooman L.A. y Young K.A. (2010) Ovarian matrix metalloproteinases are differentially regulated during the estrous cycle but not during short photoperiod induced regression in siberian hamsters (phodopus sungorus). Reprod Biol Endocrinol, 8:79.

Walters K.A., Allan C.M., Jimenez M., Lim P.R., Davey R.A., Zajac J.D., Illingworth P. y Handelsman D.J. (2007) Female mice haploinsufficient for an inactivated androgen receptor (ar) exhibit age-dependent defects that resemble the ar null phenotype of dysfunctional late follicle development, ovulation, and fertility. Endocrinology, 148:3674-3684.

Wandji S.A., Srsen V., Nathanielsz P.W., Eppig J.J. y Fortune J.E. (1997) Initiation of growth of baboon primordial follicles in vitro. Hum Reprod, 12:19932001.

Wandji S.A., Srsen V., Voss A.K., Eppig J.J. y Fortune J.E. (1996) Initiation in vitro of growth of bovine primordial follicles. Biol Reprod, 55:942-948.

Yu J.C., Heidaran M.A., Pierce J.H., Gutkind J.S., Lombardi D., Ruggiero M. y Aaronson S.A. (1991) Tyrosine mutations within the alpha platelet-derived growth factor receptor kinase insert domain abrogate receptor-associated phosphatidylinositol-3 kinase activity without affecting mitogenic or chemotactic signal transduction. $\mathrm{Mol}$ Cell Biol, 11:3780-3785.

Zhou Q., Nie R., Prins G.S., Saunders P.T.K., Katzenellenbogen B.S. y Hess R.A. (2002) Localization of androgen and estrogen receptors in adult male mouse reproductive tract. $J$ Androl, 23:870-881. 